\title{
PET probes for distinct metabolic pathways have different cell specificities during immune responses in mice
}

\author{
Evan Nair-Gill,, ${ }^{1}$ Stephanie M. Wiltzius, ${ }^{2}$ Xiao X. Wei, ${ }^{2}$ Donghui Cheng, ${ }^{2}$ Mireille Riedinger, ${ }^{1}$ \\ Caius G. Radu, ${ }^{1,3}$ and Owen N. Witte ${ }^{1,2,4,5}$
}

\begin{abstract}
${ }^{1}$ Department of Molecular and Medical Pharmacology, UCLA, Los Angeles, California, USA. ${ }^{2}$ The Howard Hughes Medical Institute, Los Angeles, California, USA. ${ }^{3}$ The Crump Institute of Molecular Imaging, Los Angeles, California, USA. ${ }^{4}$ Department of Microbiology, Immunology, and Molecular Genetics, UCLA, David Geffen School of Medicine, UCLA, Los Angeles, California, USA. ${ }^{5}$ Eli and Edythe Broad Center of Regenerative Medicine and Stem Cell Research, UCLA, Los Angeles, California, USA.
\end{abstract}

\begin{abstract}
Clinical tools that measure changes in immune cell metabolism would improve the diagnosis and treatment of immune dysfunction. PET, utilizing probes for specific metabolic processes, detects regions of immune activation in vivo. In this study we investigated the immune cell specificity of PET probes for two different metabolic pathways: $\left[{ }^{18} \mathrm{~F}\right]-2$-fluorodeoxyglucose $\left(\left[{ }^{18} \mathrm{~F}\right]-\mathrm{FDG}\right)$ for glycolysis and $\left[{ }^{18} \mathrm{~F}\right]-2$-fluoro-D-(arabinofu ranosyl)cytosine $\left(\left[{ }^{18} \mathrm{~F}\right]-\mathrm{FAC}\right)$ for deoxycytidine salvage. We isolated innate and adaptive immune cells from tissues of mice challenged with a retrovirus-induced sarcoma and measured their ability to accumulate FDG and FAC. We determined that the two probes had distinct patterns of accumulation: FDG accumulated to the highest levels in innate immune cells, while FAC accumulated predominantly in $\mathrm{CD8}^{+} \mathrm{T}$ cells in a manner that correlated with cellular proliferation. This study demonstrates that innate and adaptive cell types differ in glycolytic and deoxycytidine salvage demands during an immune response and that these differential metabolic requirements can be detected with specific PET probes. Our findings have implications for the interpretation of clinical PET scans that use $\left[{ }^{18} \mathrm{~F}\right]$-FDG or $\left[{ }^{18} \mathrm{~F}\right]-\mathrm{FAC}$ to assess immune function in vivo and suggest potential applications of metabolic PET to monitor the effects of targeted immune modulation.
\end{abstract}

\section{Introduction}

Innate and adaptive immune cells modulate the accumulation and metabolism of specific substrates to meet functional demands during a response. Macrophages and granulocytes, for example, increase expression of glucose transporters and glycolytic enzymes through HIF-1 $\alpha$ to generate energy required for phagocytosis and cytokine secretion in inflamed tissue (1). Both B and T lymphocytes switch from oxidative phosphorylation to glycolysis after antigen stimulation in order to meet biosynthetic demands during clonal expansion (2-4). Recently, it has been shown that differentiation of effector $\mathrm{T}$ cells to memory $\mathrm{T}$ cells is accompanied by a switch in energy production from glycolysis to beta oxidation of fatty acids (5). These findings indicate that measurements of specific metabolic processes in immune cells may inform about the function of the immune system during disease. The effect of therapies designed to alter immune function might also be assessed through analysis of immune cell metabolism.

PET is a noninvasive imaging modality that is capable of detecting subnanomolar concentrations of a positron-labeled probe distributed throughout the body (6). PET probes for cellular metabolic pathways enable quantitative in vivo measurements of cellular biochemistry. $\left[{ }^{18} \mathrm{~F}\right]-2$-fluorodeoxyglucose $\left(\left[{ }^{18} \mathrm{~F}\right]-\mathrm{FDG}\right)$ is a positron-labeled glucose analog that accumulates in tissues with high rates of glycolytic metabolism and is commonly used in the

Conflict of interest: Evan Nair-Gill, Caius G. Radu, and Owen N. Witte are coinvestors on patent filings for novel PET probes for immunity and cancer. Caius G. Radu and Owen N. Witte are among the co-founders of Sofie Biosciences, which has licensed this technology.

Citation for this article: J Clin Invest. 2010;120(6):2005-2015. doi:10.1172/JCI41250. clinic to measure tumor cell glucose metabolism and its response to therapy (reviewed in ref. 7).

The critical role of glycolysis in the function of many immune cell types has resulted in $\left[{ }^{18} \mathrm{~F}\right]-F D G$ PET being used to measure immune responses in vivo. In animal models, $\left[{ }^{18} \mathrm{~F}\right]$-FDG PET detects tissue-specific immune activation during experimental autoimmune encephalitis (8), colitis (9), rheumatoid arthritis (10), and graft-versus-host disease (GVHD) (11). [ $\left.{ }^{18} \mathrm{~F}\right]$-FDG PET has clinical application to visualize inflammation in atherosclerotic plaques (12), in synovial tissue during rheumatoid arthritis (13), and in the gut during GVHD (11). $\left.{ }^{18} \mathrm{~F}\right]-F D G$ PET also has utility in the diagnosis and management of numerous infectious disorders resulting in chronic osteomyelitis, fever of unknown origin, vascular graft infection, and AIDS (reviewed in ref. 14).

Glucose is an example of a substrate whose metabolism is dynamically regulated in innate and adaptive immune cells. Immune cells also require a variety of other metabolites such as essential amino acids (15), membrane (16) and nucleotide precursors, and vitamins (17). These metabolic requirements are based on a combination of cell-intrinsic metabolic programs and microenvironmental factors during an immune response. Concurrent measurements of differentially regulated metabolic pathways with PET may enable more thorough evaluation of immune cell function in vivo.

We recently developed $\left[{ }^{18} \mathrm{~F}\right]-2$-fluoro-D-(arabinofuranosyl)cytosine $\left(\left[{ }^{18} \mathrm{~F}\right]-\mathrm{FAC}\right)$, a fluorinated deoxycytidine analog that is taken up by cells and trapped in a phosphorylation-dependant manner by deoxycytidine kinase (DCK) (18). DCK is the rate-limiting step in the deoxycytidine salvage pathway, and its expression is enriched in hematolymphoid tissues (19). Animals genetically deficient for DCK are viable but have drastically reduced numbers of mature 
T cells and B cells (20). $\left[{ }^{18} \mathrm{~F}\right]$-FAC has improved immune selectivity over $\left[{ }^{18} \mathrm{~F}\right]-F D G$ in naive mice and accumulates in the major lymphoid compartments: thymus, bone marrow, and spleen (21). $\left[{ }^{18} \mathrm{~F}\right]-\mathrm{FAC}$ also accumulates in the gastrointestinal tract of mice, where, under normal conditions, it is sequestered in intestinal epithelial cells (21). PET imaging of Dck-knockout mice with $\left[{ }^{18} \mathrm{~F}\right]$-FAC shows no signal in lymphoid organs or the gastrointestinal tract. $\left[{ }^{18} \mathrm{~F}\right]-\mathrm{FAC} P E T$ signal in peripheral lymph nodes and spleens of wildtype mice increases with immune stimulation during antitumor responses and lymphoproliferative autoimmune disorders (21).

Following immune stimulation, $\left[{ }^{18} \mathrm{~F}\right]$-FDG and $\left[{ }^{18} \mathrm{~F}\right]$-FAC PET detect increased activity of two distinct metabolic pathways in vivo. Here, we defined how accumulation of each of these probes relates to the phenotype and function of immune cells during a primary immune response.

Intramuscular inoculation with the Moloney murine sarcoma virus/murine leukemia virus complex (MSV/MuLV) results in the rapid growth and regression of a nonmetastatic rhabdomyosarco$\mathrm{ma}$ (22). The antitumor response peaks 12-15 days after infection and depends upon $\mathrm{CD}^{+}$and $\mathrm{CD}^{+} \mathrm{T}$ cells that recognize specific viral epitopes in collaboration with infiltrating innate cells (23, 24). MSV/MuLV infection also stimulates B cells to produce antibodies against viral proteins (25). Hematogenous shedding of viral antigens results in immune activation in distal parts of the body, such as the spleen. This model allowed interrogation of specific cellular components of the immune system in disparate anatomical sites using in vivo PET imaging, in situ staining, cell sorting, and in vitro and in vivo cell labeling with metabolic probes.

We report that $\left[{ }^{18} \mathrm{~F}\right]-\mathrm{FDG}$ and $\left[{ }^{18} \mathrm{~F}\right]-\mathrm{FAC}$ have distinct patterns of accumulation in innate and adaptive immune cells. While FDG accumulates to high levels in innate cells from various tissues, FAC accumulates in different immune cell types, correlating with their proliferation in a site-specific manner. Our data also show that immune-deficient CB17 SCID/SCID mice challenged with MSV/ MuLV accumulate less $\left[{ }^{18} \mathrm{~F}\right]$-FDG and $\left[{ }^{18} \mathrm{~F}\right]$-FAC in lymphoid tissues compared with immune-competent mice. However, in the tumor, the accumulation of neither probe changes in immunecompetent or immune-deficient conditions. This result, combined with phenotypic data of tumor-infiltrating T cells, suggests that neither $\left[{ }^{18} \mathrm{~F}\right]-\mathrm{FDG}$ nor $\left[{ }^{18} \mathrm{~F}\right]$-FAC can efficiently label tumorinfiltrating effector $T$ cells.

This study demonstrates that innate and adaptive cell types differ in glycolytic and deoxycytidine salvage demands during an immune response and that these differential metabolic requirements may be detected with specific PET probes. Our findings have implications for the interpretation of clinical PET scans that use $\left[{ }^{18} \mathrm{~F}\right]-\mathrm{FDG}$ or $\left[{ }^{18} \mathrm{~F}\right]-\mathrm{FAC}$ to assess immune function in vivo and suggest potential applications of metabolic PET to monitor the effects of targeted immune modulation.

\section{Results}

Metabolic PET imaging with FDG and FAC detects multiple sites of immune activation during a primary antitumor response. We tested the ability of metabolic PET imaging with $\left[{ }^{18} \mathrm{~F}\right]-\mathrm{FDG}$ and $\left[{ }^{18} \mathrm{~F}\right]-\mathrm{FAC}$ to detect immune activation throughout the body after inoculation with MSV/MuLV. Immune-competent C57BL/6 mice were injected intramuscularly with $\mathrm{MSV} / \mathrm{MuLV}$ and imaged with $\left[{ }^{18} \mathrm{~F}\right]-\mathrm{FAC}$ and $\left[{ }^{18} \mathrm{~F}\right]$-FDG PET coregistered with CT on sequential days at 3 time points after infection (days 6,9 , and 13 for $\left[{ }^{18} \mathrm{~F}\right]$-FAC and days 7 , 10 , and 14 for $\left[{ }^{18} \mathrm{~F}\right]-\mathrm{FDG}$ ) (Figure $1 \mathrm{~A}$ ). Naive mice that were not challenged with MSV/MuLV were used to establish the baseline accumulation patterns for each probe.

Naive mice typically show high [18F]-FDG accumulation in the heart and brain, which rely heavily on glucose metabolism. Brain signal can vary between mice during imaging based on the time each animal spends under anesthesia (26). As was shown in the initial characterization $(27),\left[{ }^{18} \mathrm{~F}\right]$-FAC differs from $\left[{ }^{18} \mathrm{~F}\right]$-FDG in its whole-body accumulation in naive mice, with high signal levels in the spleen, thymus, bone marrow, and gastrointestinal tract. Both probes are eliminated from the blood by the kidneys and excreted from the bladder.

After infection with MSV/MuLV, $\left[{ }^{18} \mathrm{~F}\right]-\mathrm{FDG}$ accumulation was detected in the spleen and draining lymph node (DLN) 10 and 14 days after inoculation. Intense $\left[{ }^{18} \mathrm{~F}\right]-\mathrm{FDG}$ signal in the right shoulder was visible on day 10 , corresponding to the growth of the virally induced rhabdomyosarcoma. Regions of interest (ROIs) were drawn around the spleen, lymph node, and tumor. The average signal intensity in an ROI was calculated from the percent injected dose per gram and normalized to the average signal intensity in an ROI drawn around uninfected muscle, which exhibited low physiologic probe accumulation. The data are presented as fold increase over background (Figure 1B). There was an approximately 5 -fold increase in $\left[{ }^{18} \mathrm{~F}\right]-F D G$ accumulation in the spleen and an approximately 8-fold increase in the DLN compared with naive animals at 10 days after inoculation. These signals remained at similar levels when measured on day 14 . A small increase in $\left[{ }^{18} \mathrm{~F}\right]$-FDG signal in the DLN was observed 7 days after inoculation. $\left[{ }^{18} \mathrm{~F}\right]$-FDG accumulation in the rhabdomyosarcoma muscle of infected mice was more than approximately 10 -fold over that in muscle tissue of naive mice by day 10 after infection and remained elevated at day 14 .

$\left[{ }^{18} \mathrm{~F}\right]-\mathrm{FAC}$ accumulation in the spleen and DLN could be detected on day 9 after inoculation. This corresponded to approximately 7 -fold and approximately 2 -fold increases in normalized signal intensity in these tissues, respectively. The signals in both these tissues remained above background when measured on day 13 . Small increases in $\left[{ }^{18} \mathrm{~F}\right]$-FAC signal could be detected in the spleen and the DLN on day 6 after infection. In contrast to the results with $\left[{ }^{18} \mathrm{~F}\right]-\mathrm{FDG}$, there was little probe accumulation in the tumor compared with muscle tissue in naive mice over the course of $\mathrm{MSV} / \mathrm{MuLV}$ infection.

Inoculation with $M S V / M u L V$ leads to increased density of diverse immune cell types in lymphoid organs and transformed muscle tissue. $\mathrm{MSV} / \mathrm{MuLV}$ challenge results in the activation and mobilization of multiple immune cell types. The metabolic PET signals observed during infection may reflect changes in the density of various immune cells in tissues. In order to assess the distribution of different immune cell types, we removed the spleen, DLN, and tumor 14 days after MSV/MuLV infection, then cryosectioned and stained these tissues with antibodies against cell surface antigens present on innate and adaptive immune cell subsets (Figure 2A). The spleen, lymph nodes, and muscle from unchallenged mice were harvested and stained for comparison with the immune-activated state. We counted the number of positively stained cells in 10 random $\times 40$ fields of view from at least 3 different tissue sections. The average counts were normalized to the surface area of the field of view and presented as an average cell density of the number of cells per square millimeter (cells $/ \mathrm{mm}^{2}$ ) (Figure $2 \mathrm{~B}$ ).

We observed that $\mathrm{CD}^{+} \mathrm{T}$ cells increased approximately 3 -fold in density in the spleen and approximately 9-fold in the DLN 14 days after MSV/MuLV infection. There was also infiltration of 
A

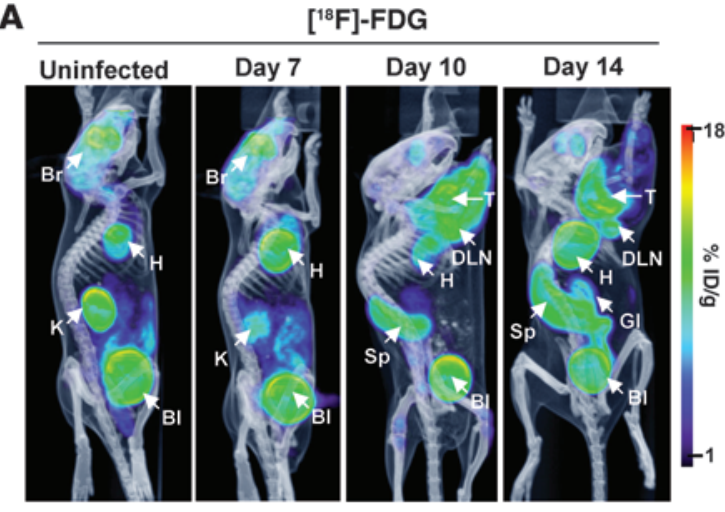

$\left[{ }^{18} \mathrm{~F}\right]-\mathrm{FAC}$

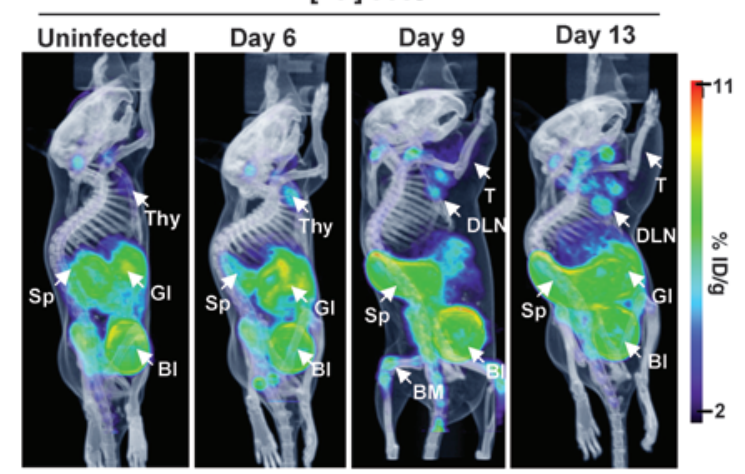

B

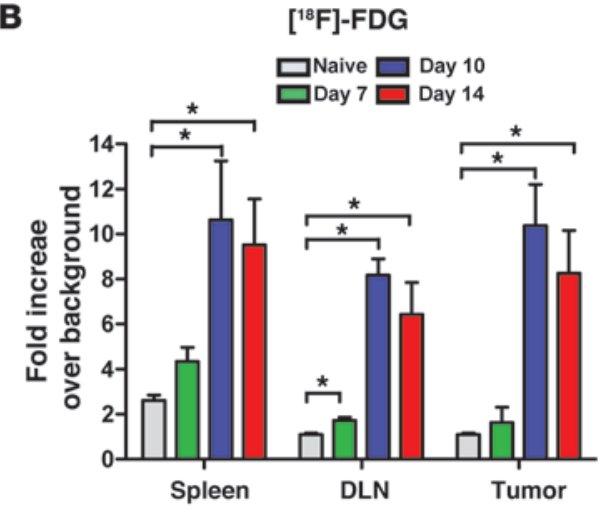

$\left[{ }^{18} \mathrm{~F}\right]-\mathrm{FAC}$

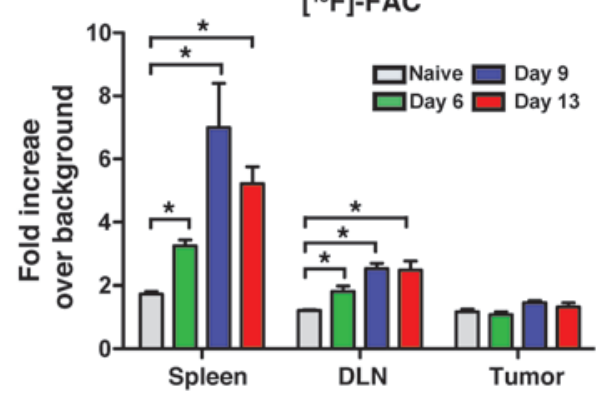

Figure 1

Metabolic PET imaging with [ $\left.{ }^{18} \mathrm{~F}\right]-\mathrm{FDG}$ and $\left[{ }^{18} \mathrm{~F}\right]-\mathrm{FAC}$ detects multiple sites of immune activation during a primary antitumor response. (A) Immunocompetent C57BL/6 mice were injected intramuscularly with the MSV/MuLV retroviral complex and imaged with [ $\left.{ }^{18} \mathrm{~F}\right]$-FDG on days 7 , 10 , and 14 and $\left[{ }^{18} \mathrm{~F}\right]-\mathrm{FAC}$ on days 6,9 , and 13 after inoculation. $\left[{ }^{18} \mathrm{~F}\right]-\mathrm{FDG}$ and $\left[{ }^{18} \mathrm{~F}\right]-\mathrm{FAC}$ PET images of unchallenged C57BL/6 mice are shown as controls ( $n=3$ for each group). Br, brain; H, heart; K, kidney; BI, bladder; T, tumor; Sp, spleen; Gl, gastrointestinal tract; Thy, thymus; \%ID/g, percent injected dose per gram. (B) Quantification of PET signal in the spleen, DLN, and tumor $\left({ }^{*} P<0.05\right)$.

$\mathrm{CD}^{+} \mathrm{T}$ cells into the sarcoma (approximately 400 cells $/ \mathrm{mm}^{2}$ ). No immune cells were detected in the uninfected muscle. The density of $\mathrm{CD}^{+} \mathrm{T}$ cells in the spleen and DLN increased approximately 3 -fold upon viral infection, and there was marked infiltration of these cells into the tumor $\left(\sim 800\right.$ cells $\left./ \mathrm{mm}^{2}\right)$. B cell density in the spleen was consistent between naive and MSV/MuLV-infected conditions but increased approximately 3 -fold in the DLN. Very few $B$ cells were detected in the sarcoma. The density of innate immune cells stained with CD11b in the spleen was similar in naive and MSV/MuLV-infected mice. The density of these cells in the DLN, however, increased approximately 10 -fold during infection, and they could be observed infiltrating the tumor $\left(\sim 500\right.$ cells $\left./ \mathrm{mm}^{2}\right)$. A comparison of the relative densities of each cell type in specific tissues is shown in Supplemental Figure 1 (supplemental material available online with this article; doi:10.1172/JCI41250DS1).

To validate the distribution of $\left[{ }^{18} \mathrm{~F}\right]-\mathrm{FDG}$ and $\left[{ }^{18} \mathrm{~F}\right]-\mathrm{FAC}$ in tissues with higher resolution, we performed whole-body autoradiography (Figure 2C). Mice bearing day $14 \mathrm{MSV} / \mathrm{MuLV}$ tumors were injected with $1 \mathrm{mCi}$ of $\left[{ }^{18} \mathrm{~F}\right]-\mathrm{FDG}$ or $\left[{ }^{18} \mathrm{~F}\right]-\mathrm{FAC}$, embedded in carboxymethylcellulose, and frozen. Whole-body coronal sections $(20 \mu \mathrm{m})$ were cut and then exposed on BAS-TR2025 phosphor imaging screens. $\left[{ }^{18} \mathrm{~F}\right]-\mathrm{FDG}$ showed homogeneous accumulation in the tumor, except in necrotic areas near the center. $\left[{ }^{18} \mathrm{~F}\right]-\mathrm{FDG}$ signal in the DLN could be detected discretely from tumor sig- nal. $\left[{ }^{18} \mathrm{~F}\right]-$ FDG signal in the spleen was heterogeneous. The most intense regions of signal appeared to correspond to areas of white pulp that were visible in splenic cross sections.

A homogeneous low-intensity signal was observed in the tumor with $\left[{ }^{18} \mathrm{~F}\right]$-FAC autoradiography. Uniformly intense DLN signals were localized adjacent to the tumor. $\left[{ }^{18} \mathrm{~F}\right]$-FAC signal in the spleen saturated the phosphor imager, making it difficult to assess probe distribution within this organ.

Cell-intrinsic $\left[{ }^{3} \mathrm{H}\right]-2$-deoxy-D-glucose accumulation is highest in innate immune cells, while $\left[{ }^{3} \mathrm{H}\right]-\mathrm{FAC}$ accumulates predominantly in $\mathrm{CD}^{+} \mathrm{T}$ cells. Radiologic and microscopic analyses showed that tissues accumulating $\left[{ }^{18} \mathrm{~F}\right]-\mathrm{FDG}$ and/or $\left[{ }^{18} \mathrm{~F}\right]-\mathrm{FAC}$ during PET imaging contained heterogeneous mixtures of diverse immune cell types. To define which immune cell types could sequester [ $\left.{ }^{18} \mathrm{~F}\right]-\mathrm{FDG}$ and $\left[{ }^{18} \mathrm{~F}\right]-\mathrm{FAC}$, the spleen, DLN, and tumor were harvested from immune-competent mice 14 days after MSV/MuLV infection. These tissues were dissociated into single-cell suspensions for cell sorting of innate and adaptive cell types (Figure $3 \mathrm{~A}$ ). $\mathrm{CD}^{+} \mathrm{T}$ cells and $\mathrm{CD} 11 \mathrm{~b}$ hi myeloid cells were isolated from dissociated tumors. CD4 ${ }^{+} \mathrm{T}$ cells, $\mathrm{CD}^{+} \mathrm{T}$ cells, and B cells were isolated from the DLN. CD4 ${ }^{+} \mathrm{T}$ cells, $\mathrm{CD}^{+} \mathrm{T}$ cells, B cells, and CD11 bhi myeloid cells were isolated from the spleen. The low number of $\mathrm{CD} 11 \mathrm{~b}^{\text {hi }}$ cells recovered from the $\mathrm{DLN}$ and $\mathrm{CD} 4^{+} \mathrm{T}$ cells recovered from the tumor prevented further analysis (Figure 3B). Cell-intrinsic sequestration of glycolytic and 
A
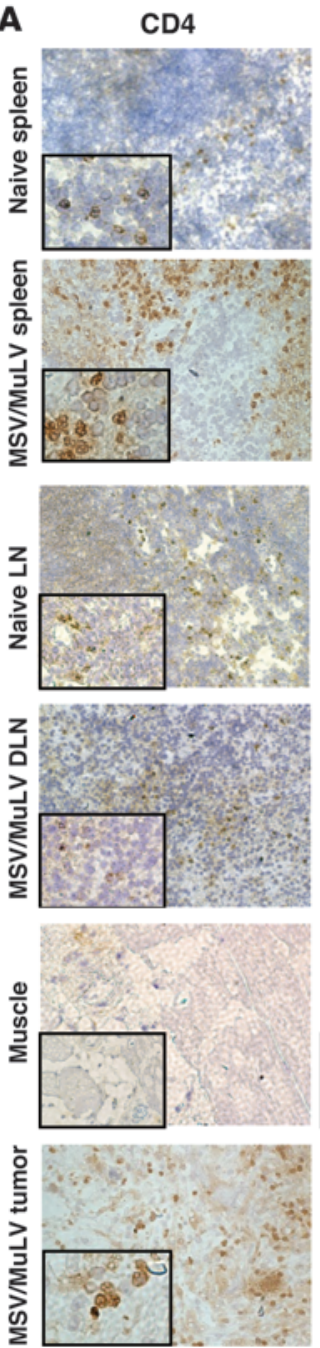

CD8
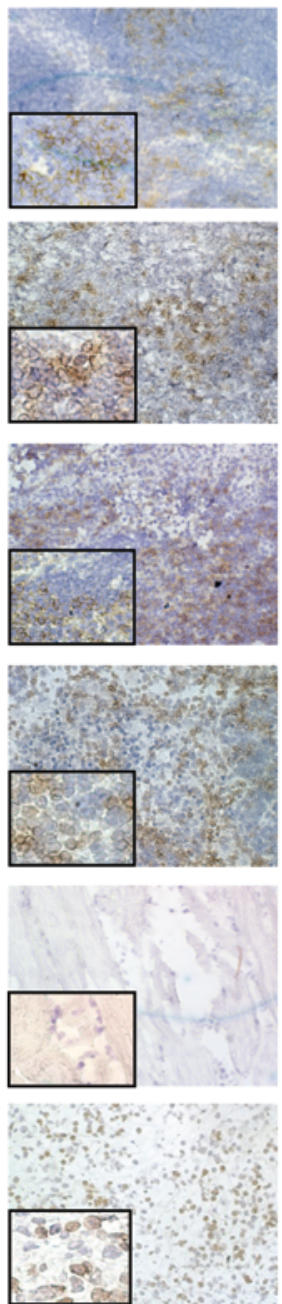

B220
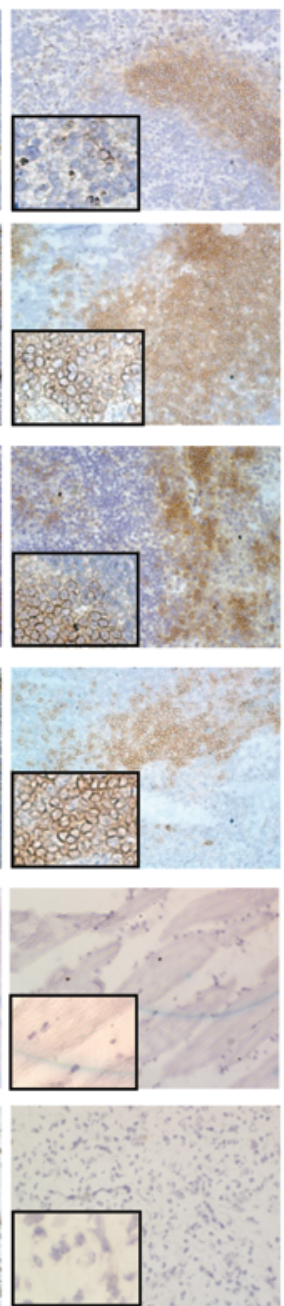
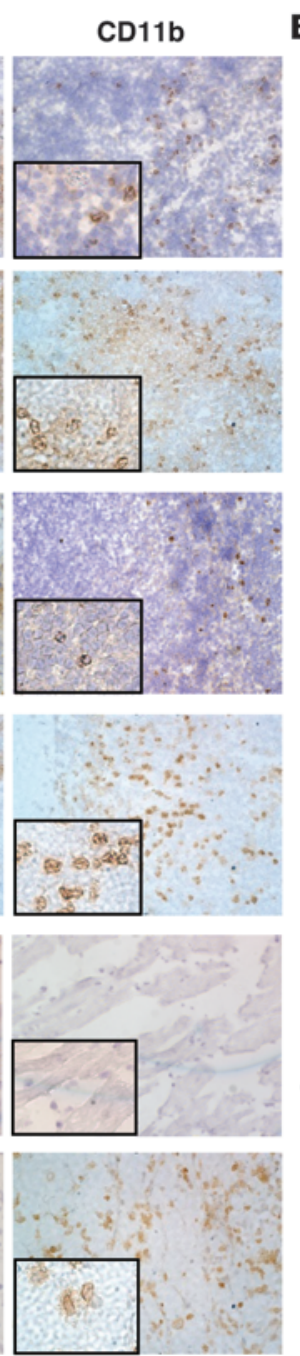
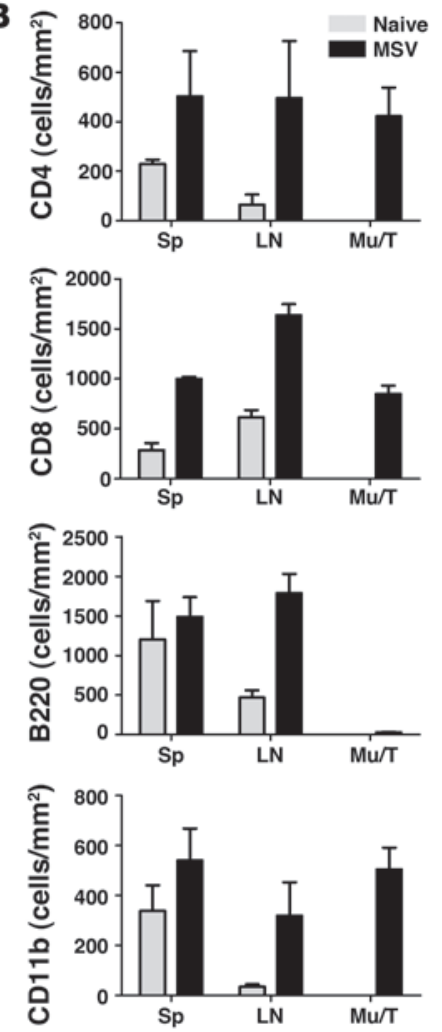

C

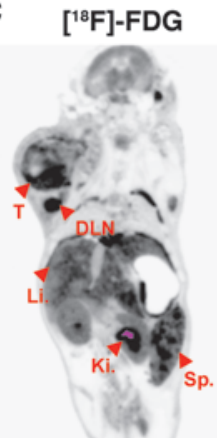

$\left[{ }^{18} \mathrm{~F}\right]-\mathrm{FAC}$

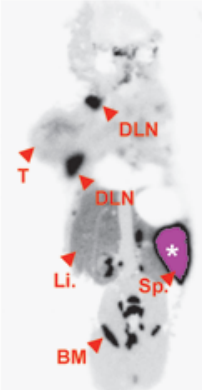

Figure 2

Inoculation with MSV/MuLV leads to increased density of diverse immune cell types in lymphoid organs and transformed muscle tissue. (A) Tumor, DLN, and spleens were harvested from MSV/MuLV-infected mice 14 days after inoculation, at the peak of the antitumor response, sectioned, and stained with antibodies for CD4, CD8, B220, and CD11b (original magnification: $\times 20$; insets, $\times 40$ ). Corresponding tissue from uninfected mice were stained for comparison. (B) Quantification of the density of positively stained cells in tissues from naive and MSV/MuLVinfected mice (3 sections for each stain). (C) Whole-body coronal sections for autoradiographic validation of $\left[{ }^{18} \mathrm{~F}\right]-\mathrm{FDG}$ and $\left[{ }^{18} \mathrm{~F}\right]-\mathrm{FAC}$ accumulation in tissues during MSV/MuLV infection (asterisk indicates saturated region on detector). Mu/T, muscle/tumor; Li, liver.

deoxycytidine salvage probes in sorted cell population was measured in parallel using an ex vivo probe accumulation assay. A total of $10^{5}$ of each cell type were placed in wells of a microtiter plate and pulse labeled with $\left[{ }^{3} \mathrm{H}\right]-2$-deoxy-D-glucose $\left(\left[{ }^{3} \mathrm{H}\right]-2 \mathrm{DG}\right)$ or $\left[{ }^{3} \mathrm{H}\right]-$ FAC for 1 hour. $\left[{ }^{18} \mathrm{~F}\right]-\mathrm{FDG}$ and $\left[{ }^{18} \mathrm{~F}\right]-\mathrm{FAC}$ PET images of unchallenged mice exhibited background signal in the lymph nodes (Figure 1A); thus, we used single-cell suspensions of naive lymph nodes to establish a baseline for probe accumulation. Radiation counts were normalized to the specific activity of each probe and presented as femtomoles per $10^{5}$ cells. Data from 3 independent sorting experiments were combined (Figure 3, C and D).
We found that $\left[{ }^{3} \mathrm{H}\right]-2 \mathrm{DG}$ preferentially accumulated in innate cell types that stained CD11bhi (Figure 3C). CD11b is a pan-myeloid marker present on both macrophages and granulocytes. Further analysis of the myeloid cell populations showed that the tumor and the spleen contained a mixture of macrophages and granulocytes based on positive staining with antibodies against $\mathrm{F} 4 / 80$ and $\mathrm{Gr}-1$, respectively (data not shown). Compared with the spleen, the tumor samples contained fewer granulocytes and were enriched for macrophages, as evidenced by diminished Gr- 1 expression and increased F4/80 expression (data not shown). Tumor-infiltrating CD11b ${ }^{\text {hi }}$ myeloid cells exhibited approximately 4 -fold more 
A

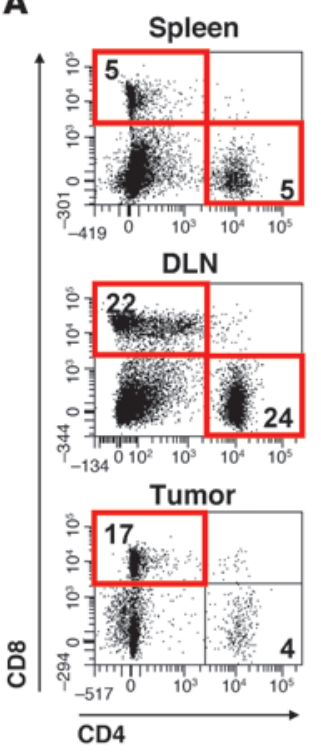

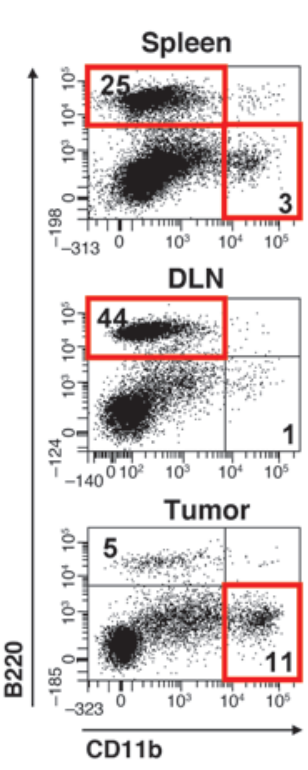

B
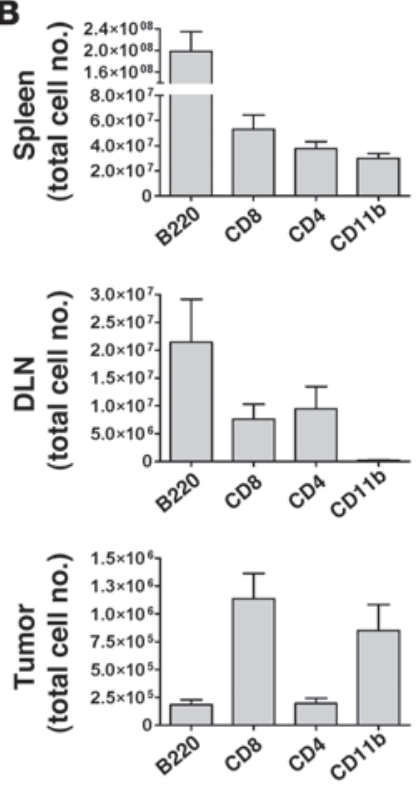

C
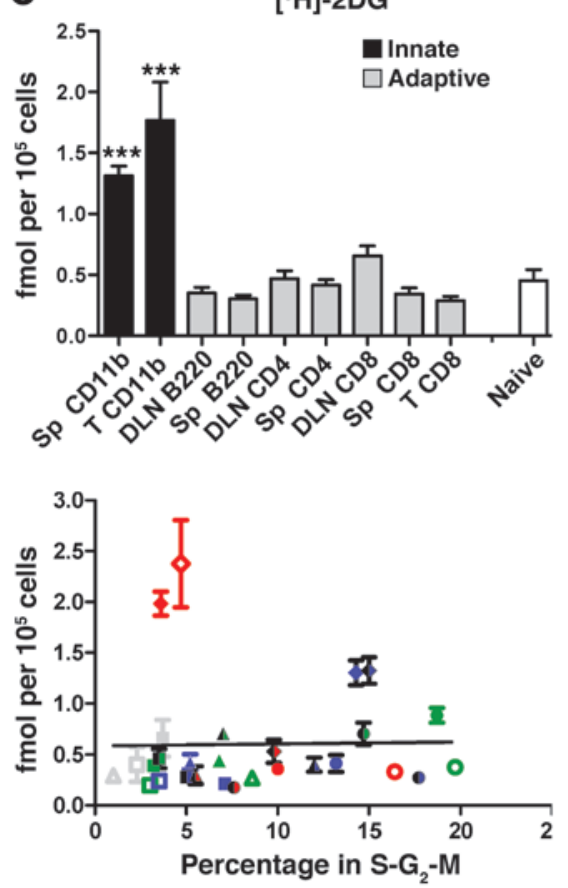

D
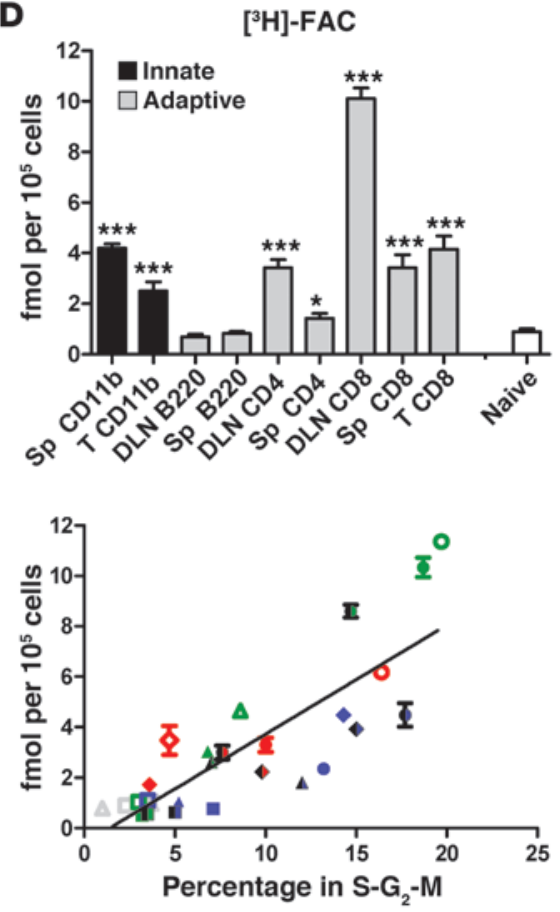

\section{Figure 3}

Cell-intrinsic $\left[{ }^{3} \mathrm{H}\right]-2 \mathrm{DG}$ accumulation is highest in innate immune cells, while $\left[{ }^{3} \mathrm{H}\right]-\mathrm{FAC}$ accumulates predominantly in adaptive immune cells. (A) Single-cell suspensions of spleen, DLN, and tumor from MSV/MuLVinfected mice were analyzed for CD4, CD8, B220, and CD11b by flow cytometry. Populations that were collected for probe accumulation analysis are boxed in red. Values in the quadrants represent the percentage of major immune lineages isolated from each tissue. (B) The total number of each cell type recovered from the spleen, DLN, and tumor are shown ( $n=6$ mice). (C and $\mathbf{D}$ ) Cells $\left(10^{5}\right)$ from the sorted populations were pulse labeled with $\left[{ }^{3} \mathrm{H}\right]-2 \mathrm{DG}(\mathbf{C})$ or $\left[{ }^{3} \mathrm{H}\right]-\mathrm{FAC}$ (D) and compared with naive lymphocytes ( ${ }^{\star \star *} P<0.0001,{ }^{\star} P<0.05, n=3$ experiments). Sorted cells were fixed and stained with propidium iodide. The percentage in $S-G_{2}-M$ was plotted against the accumulation of $\left[{ }^{3} \mathrm{H}\right]-$ $2 \mathrm{DG}$ and $\left[{ }^{3} \mathrm{H}\right]-\mathrm{FAC}$. Data from 3 experiments are shown. Open, filled, and half-filled symbols represent 3 experiments. Shapes were assigned according to cell type: squares, B cells; triangles, CD4+ T cells; circles, CD8+ T cells; diamonds, CD11 bi myeloid cells. Colors were assigned based on the tissues from which a cell population was isolated: blue, spleen; green, DLN; red, tumor; gray, naive lymph nodes. A positive correlation between $\left[{ }^{3} \mathrm{H}\right]-\mathrm{FAC}$ accumulation and percent in $\mathrm{S}-\mathrm{G}_{2}-\mathrm{M}$ was observed $\left(r^{2}=0.68\right.$, $P<0.0001$ ). $\left[{ }^{3} \mathrm{H}\right]-2 \mathrm{DG}$ accumulation per cell than the naive lymphocyte control. Myeloid cells isolated from the spleen of infected animals accumulated approximately 3 -fold more $\left[{ }^{3} \mathrm{H}\right]-2 \mathrm{DG}$ per cell than the control. Accumulation of $\left[{ }^{3} \mathrm{H}\right]-2 \mathrm{DG}$ in the adaptive immune cell types was not substantially changed compared with the naive control.

There was a striking difference in the accumulation of $\left[{ }^{3} \mathrm{H}\right]-\mathrm{FAC}$ versus $\left[{ }^{3} \mathrm{H}\right]-2 \mathrm{DG}$ in the panel of primary cells tested. $\left[{ }^{3} \mathrm{H}\right]-\mathrm{FAC}$ accumulated in both innate and adaptive cell types isolated from the different tissues of MSV/MuLV-infected animals (Figure 3D). $\mathrm{CD}^{+}$ $\mathrm{T}$ cells from the DLN accumulated the highest levels of $\left[{ }^{3} \mathrm{H}\right]-\mathrm{FAC}$, approximately 11 -fold greater than in the naive control. $\left[{ }^{3} \mathrm{H}\right]-\mathrm{FAC}$ also accumulated in tumor and spleen $\mathrm{CD}^{+} \mathrm{T}$ cells, DLN CD4 ${ }^{+}$ $\mathrm{T}$ cells, and CD11b $\mathrm{b}^{\text {hi }}$ myeloid cells from the tumor and spleen at lev- els greater than the naive control. In these experiments, the magnitude of $\left[{ }^{3} \mathrm{H}\right]$-FAC accumulation in these populations was approximately 2- to 3-fold lower than in the DLN CD8 ${ }^{+} \mathrm{T}$ cells. B cells from the DLN and spleen and $\mathrm{CD}^{+} \mathrm{T}$ cells from the spleen accumulated amounts of $\left[{ }^{3} \mathrm{H}\right]-\mathrm{FAC}$ equivalent to the naive lymphocyte control.

Increased activity of glycolytic and nucleoside salvage pathways have been linked to proliferation of multiple innate and adaptive immune cell types during in vitro stimulation with mitogens (3, $4,28)$. To determine whether cell-intrinsic accumulation of $\left[{ }^{3} \mathrm{H}\right]-$ $2 \mathrm{DG}$ or $\left[{ }^{3} \mathrm{H}\right]$-FAC correlated with immune cell proliferation, we used propidium iodide staining to measure the proportion of sorted cells that were in $\mathrm{S}_{-} \mathrm{G}_{2}-\mathrm{M}$ of the cell cycle. $\left[{ }^{3} \mathrm{H}\right]-2 \mathrm{DG}$ and $\left[{ }^{3} \mathrm{H}\right]-\mathrm{FAC}$ accumulation in cell populations from 3 independent 
A

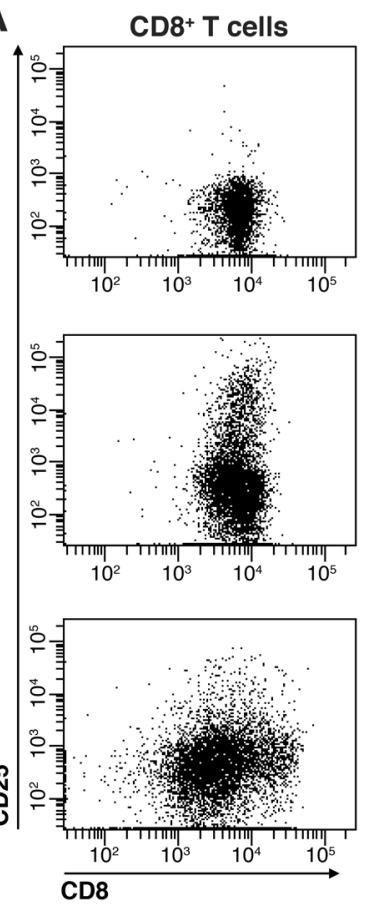

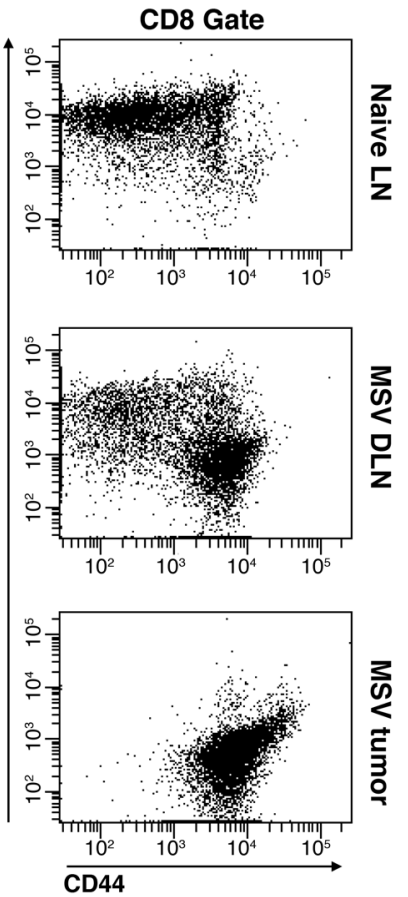

B
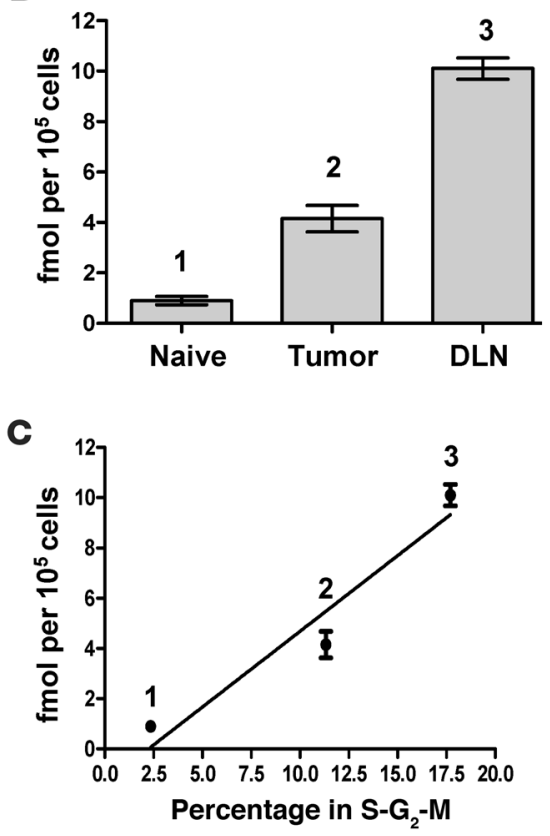

\section{Figure 4}

Cytotoxic T cell populations with different activation phenotypes vary in their capacity to accumulate FAC. (A) Analysis of the activation status of CD8 ${ }^{+} T$ cells sorted from the tumor and DLNs based on surface expression of CD25, CD44, and CD62L. CD8 ${ }^{+} T$ cells from unchallenged animals are shown as controls (naive). (B) [ $\left.{ }^{3} \mathrm{H}\right]-F A C$ accumulation in $\mathrm{CD} 8^{+} \mathrm{T}$ cells isolated from the tumor and DLNs of MSV/MuLV-infected mice and from the lymph nodes of naive mice (same cell populations as in Figure $2 \mathrm{~B}$ ). (C) $\left[{ }^{3} \mathrm{H}\right]-\mathrm{FAC}$ accumulation in $\mathrm{CD} 8^{+} \mathrm{T}$ cells from different anatomical sites plotted against the average percentage of those cells in $\mathrm{S}-\mathrm{G}_{2}-\mathrm{M}$ of the cell cycle from 3 independent experiments.

experiments was plotted against the percentage of cells in that population in $\mathrm{S}-\mathrm{G}_{2}-\mathrm{M}$ (Figure 3, C and D). Ex vivo cellular accumulation of $\left[{ }^{3} \mathrm{H}\right]-2 \mathrm{DG}$ was skewed toward myeloid cells and did not correlate with the proportion of cells in $\mathrm{S}-\mathrm{G}_{2}-\mathrm{M}$. In contrast, there was a significant positive correlation between the magnitude of cellular $\left[{ }^{3} \mathrm{H}\right]-\mathrm{FAC}$ accumulation and the percentage of cells in S-G2-M $\left(r^{2}=0.69, P<0.001\right)$.

Cytotoxic $T$ cell populations with different activation phenotypes vary in their capacity to accumulate $\left[{ }^{3} \mathrm{H}\right]-F A C .\left[{ }^{3} \mathrm{H}\right]-\mathrm{FAC}$ accumulation in $\mathrm{CD}^{+} \mathrm{T}$ cell populations during the anti-MSV/MuLV response suggested that this probe may have utility in tracking activated cytotoxic lymphocytes from lymphoid organs to target tissues. We analyzed the activation phenotype of $\mathrm{CD}^{+} \mathrm{T}$ cells isolated from lymph nodes of naive mice and from the DLNs and tumors of MSV/MuLV-infected mice based on cell surface expression of CD25 (the $\alpha$ chain of the IL-2 receptor), CD44 (a hyaluronic acid receptor that aids lymphocyte trafficking to target tissues), and CD62L (the lymph node homing receptor). Naive $\mathrm{CD}^{+} \mathrm{T}$ cells express low levels of CD25 and CD44 and express high levels of CD62L. Soon after activation, T cells upregulate surface expression of CD25 (reviewed in ref. 29). As they transition to become effector-memory cells, activated T cells upregulate CD44 expression and lose expression of CD62L (reviewed in ref. 30).

$\mathrm{CD}^{+} \mathrm{T}$ cells from unchallenged mice lacked CD25 expression and had the $\mathrm{CD} 44^{\mathrm{lo}} \mathrm{CD} 62 \mathrm{~L}^{\text {hi }}$ naive phenotype (Figure $\left.4 \mathrm{~A}\right)$. On day 14 of the anti-MSV/MuLV response, the $\mathrm{CD} 8^{+} \mathrm{T}$ cell population in the DLN contained a mixture of CD $44^{\text {lo }} \mathrm{CD} 62 \mathrm{~L}^{\text {hi }}$ naive cells and

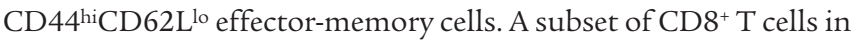

the DLN were $\mathrm{CD} 25^{\text {hi }}$. The $\mathrm{CD}^{+} \mathrm{T}$ cell population in the tumor was composed almost entirely of CD $44{ }^{\text {hi }} \mathrm{CD} 62 \mathrm{~L}^{\text {lo }}$ effector-memory cells, and few cells in this population were CD25 hi.

Cytotoxic $\mathrm{T}$ cell populations from the DLN and tumor differed in their activation phenotype. We then assessed how $\mathrm{CD}^{+} \mathrm{T}$ cell activation phenotype was related to deoxycytidine salvage activity. $\left[{ }^{3} \mathrm{H}\right]$-FAC accumulation data from Figure $3 \mathrm{D}$ were extracted to compare $\mathrm{CD}^{+} \mathrm{T}$ cells in the tumor and DLN and naive lymphocytes (Figure 4B). CD8 ${ }^{+} \mathrm{T}$ cells in the tumor accumulated less $\left[{ }^{3} \mathrm{H}\right]$-FAC per cell than those in the DLN (greater than 2-fold decrease). However, $\mathrm{CD}^{+} \mathrm{T}$ cells in the tumor still accumulated approximately 5 -fold more probe than the naive lymphocyte control. We observed that, on average, proportionately fewer of these tumor-infiltrating $\mathrm{CD}^{+} \mathrm{T}$ cells were in $\mathrm{S}-\mathrm{G}_{2}-\mathrm{M}$ of the cell cycle when compared with DLN CD8 ${ }^{+} \mathrm{T}$ cells (Figure 4C). This was consistent with our observation that tumor-infiltrating $\mathrm{CD}^{+}$ $\mathrm{T}$ cells expressed predominantly an effector-memory phenotype and had mostly lost expression of CD25, a high-affinity isoform of the IL-2 receptor that facilitates the early $\mathrm{T}$ cell proliferative response to mitogenic signals. Thus, intracellular FAC accumulation may reflect shifts in requirements by $\mathrm{T}$ cells for deoxycytidine salvage activity as they differentiate from naive cells through early effector stages to effector-memory states.

$\left[{ }^{3} \mathrm{H}\right]-2 D \mathrm{G}$ accumulation and Glut 1 expression in T cell populations activated in vivo is lower than that in T cells stimulated with anti-CD3 and $I L-2$. Ex vivo analysis demonstrated that different immune cell types preferentially accumulated probes for distinct metabolic pathways in a cell-autonomous manner. In this assay, $\mathrm{CD}^{+}$and 

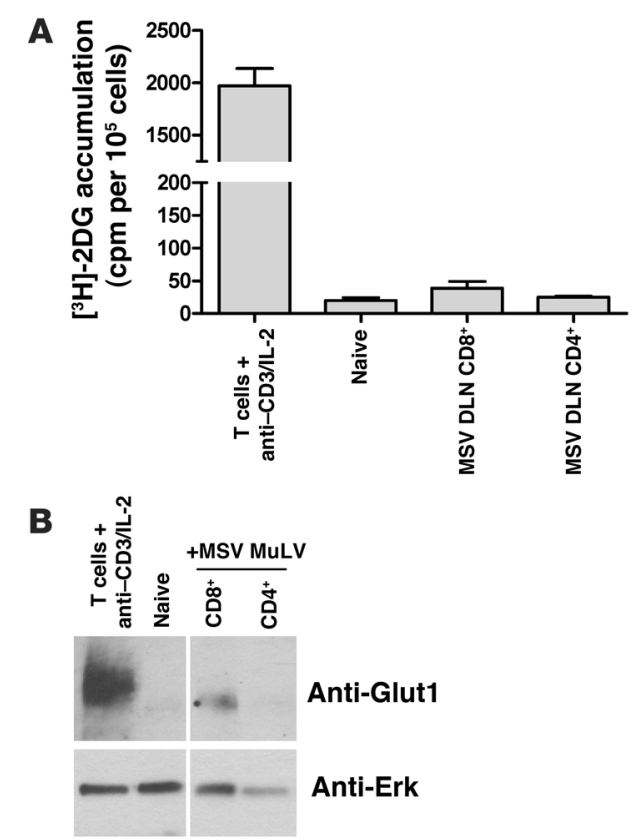

$\mathrm{CD}^{+} \mathrm{T}$ cells from the DLN, spleen, and tumor of infected mice retained relatively little $\left[{ }^{3} \mathrm{H}\right]-2 \mathrm{DG}$. This finding was unexpected, as extensive evidence has demonstrated that $\mathrm{T}$ cells rely on high rates of glucose accumulation and metabolism via aerobic glycolysis for energy production and biosynthesis during activation (reviewed in ref. 2). The experimental approaches used in these studies measured glucose metabolism in $\mathrm{T}$ cell populations that were stimulated in vitro. We speculated that in vivo activation of $\mathrm{T}$ cells with $\mathrm{MSV} / \mathrm{MuLV}$ would result in a smaller fraction of cells that were glycolytically active compared with $\mathrm{T}$ cell populations activated in vitro. We stimulated total mouse splenocytes with anti-CD3 and IL-2 for 48 hours and compared accumulation of $\left[{ }^{3} \mathrm{H}\right]-2 \mathrm{DG}$ in these cells with that in $\mathrm{CD}^{+}$and $\mathrm{CD}^{+} \mathrm{T}$ cells isolated from the DLN of MSV/MuLV-infected mice and in naive lymphocytes (Figure 5A). In vitro $\mathrm{T}$ cell stimulation with mitogens resulted in a significant increase in $\left[{ }^{3} \mathrm{H}\right]-2 \mathrm{DG}$ accumulation compared with naive lymphocytes. In keeping with our earlier findings, cellular $\left[{ }^{3} \mathrm{H}\right]-2 \mathrm{DG}$ accumulation in DLN $\mathrm{CD}^{+}$and $\mathrm{CD} 4^{+} \mathrm{T}$ cells was not substantially enhanced over the naive lymphocyte control.

\section{Figure 5}

$\left[{ }^{3} \mathrm{H}\right]-2 \mathrm{DG}$ accumulation and Glut1 expression in T cell populations activated in vivo are lower than in T cells stimulated with anti-CD3 and IL-2. (A) T cells stimulated in vitro with anti-CD3 and IL-2 were compared with $\mathrm{CD}^{+}$and $\mathrm{CD} 4^{+} \mathrm{T}$ cells from the DLN of MSV/MuLV-infected mice and naive lymphocytes for $\left[{ }^{3} \mathrm{H}\right]-2 \mathrm{DG}$ accumulation. (B) Evaluation of Glut1 expression by Western blot. Noncontiguous lanes on the gel are indicated by the white line.

The glucose transporter Slc2a1 (Glut1) is a major regulator of glucose uptake in $\mathrm{T}$ cells upon activation $(31,32)$. We analyzed the relative levels of Glut 1 expression among in vitro stimulated $\mathrm{T}$ cells, $\mathrm{CD}^{+}$and $\mathrm{CD}^{+} \mathrm{T}$ cells from the DLN of infected mice, and naive lymphocytes (Figure 5B). Glut1 was expressed at high levels in in vitro stimulated $\mathrm{T}$ cells and was not detected in naive lymphocytes. Glut 1 expression was detected in $\mathrm{CD}^{+} \mathrm{T}$ cells from the DLN, but the level of expression was much lower than that in the population activated in vitro. Glut 1 expression was not detected in $\mathrm{CD}^{+} \mathrm{T}$ cells from the DLN. These results suggest that a much smaller fraction of $\mathrm{CD}^{+} \mathrm{T}$ cells are glycolytically active during the anti-MSV/MuLV response compared with in vitro mitogenic stimulation and that this metabolic activity cannot be appreciated with ex vivo $\left[{ }^{3} \mathrm{H}\right]-2 \mathrm{DG}$ pulse labeling.

$\left[{ }^{18} \mathrm{~F}\right]-F D G$ and $\left[{ }^{18} \mathrm{~F}\right]-\mathrm{FAC}$ differentially accumulate in innate and adaptive immune cell types in vivo. To assess the sequestration of $\left[{ }^{18} \mathrm{~F}\right]-\mathrm{FDG}$ within immune cells during the anti-MSV/MuLV response with greater sensitivity, we measured intracellular probe accumulation in vivo (Figure 6). Four mice infected with MSV/MuLV 12-15 days previously were injected with $\left[{ }^{18} \mathrm{~F}\right]-\mathrm{FDG}$ and then sacrificed after 1 hour. The spleen, DLN, and tumor were harvested from each mouse, and the immune cells were isolated as before. The amount of radioactivity in each cell type was measured with by gamma counting. For comparison, analysis of $\left[{ }^{18} \mathrm{~F}\right]-\mathrm{FAC}$ accumulation was performed on an independent set of $4 \mathrm{MSV} / \mathrm{MuLV}$-infected mice. Similar numbers of each cell type were analyzed with both probes. In addition, 3 uninfected mice were injected with each probe, and total lymphocytes were isolated and measured to provide a baseline for probe accumulation.

In the spleen of MSV/MuLV-infected mice, CD11bi myeloid cells accumulated the most $\left[{ }^{18} \mathrm{~F}\right]-\mathrm{FDG}$ per cell (Figure 6). Both $\mathrm{CD}^{+}$ and $\mathrm{CD}^{+} \mathrm{T}$ cells in the spleen retained higher levels of $\left[{ }^{18} \mathrm{~F}\right]-\mathrm{FDG}$ than did naive lymphocytes. [ $\left.{ }^{18} \mathrm{~F}\right]$-FDG accumulation in $\mathrm{B}$ cells was not found to occur at levels substantially greater than the naive
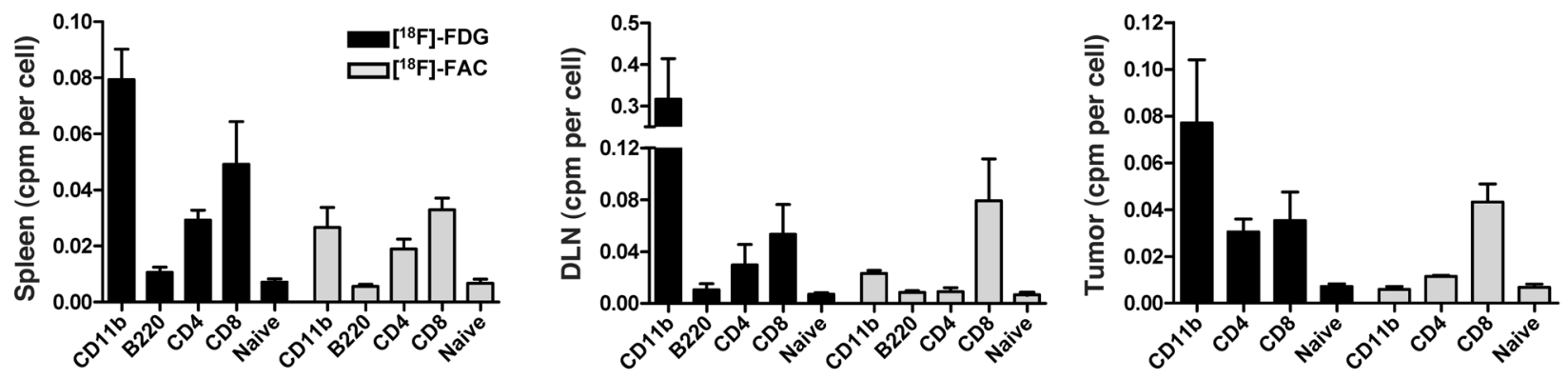

Figure 6

$\left[{ }^{18} \mathrm{~F}\right]-\mathrm{FDG}$ and $\left[{ }^{18} \mathrm{~F}\right]-\mathrm{FAC}$ differentially accumulate in innate and adaptive immune cell types in vivo. MSV/MuLV-infected animals were injected with $1 \mathrm{mCi}$ of $\left[{ }^{18} \mathrm{~F}\right]-\mathrm{FDG}$ or $\left[{ }^{18} \mathrm{~F}\right]-\mathrm{FAC}$ ( $n=4$ for each probe). The spleen, DLN, and tumors were dissociated, innate and adaptive immune cells were isolated, and the amount of radioactivity per cell in each cell type was quantified by gamma counting. Naive lymphocytes from unchallenged mice injected with each probe were measured as controls ( $n=3$ for each probe). 
A
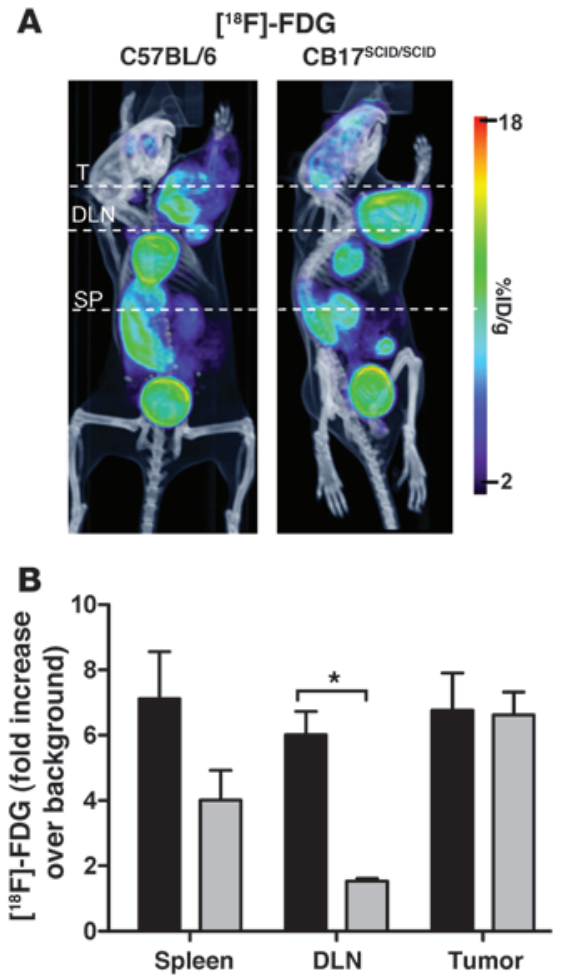
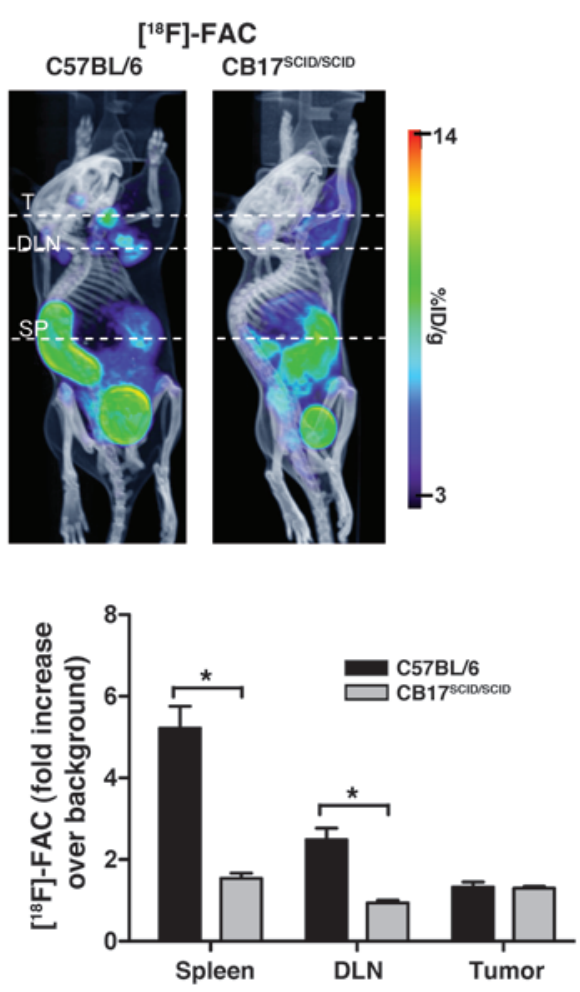

Figure 7

A defective adaptive immune response leads to reduced $\left[{ }^{18} \mathrm{~F}\right]-\mathrm{FDG}$ and $\left[{ }^{18} \mathrm{~F}\right]-\mathrm{FAC}$ signal in lymphoid organs but not the tumor. (A) CB17 $\mathrm{SCID/SCID}$ immune-defective mice were challenged with MSV/MuLV and imaged with $\left[{ }^{18} \mathrm{~F}\right]-\mathrm{FDG}$ and $\left[{ }^{18} \mathrm{~F}\right]-\mathrm{FAC}$ PET. Scans of immune-competent C57BL/6 mice challenged with MSV/MuLV during the same experiment are shown for comparison with each probe. (B) A quantitative comparison of [ $\left.{ }^{18} \mathrm{~F}\right]-\mathrm{FDG}$ and $\left[{ }^{18} \mathrm{~F}\right]-\mathrm{FAC}$ probe accumulation in the tumor regions of $\mathrm{C} 57 \mathrm{BL} / 6$ and $\mathrm{CB} 17 \mathrm{SCID} / \mathrm{SCID}$ mice $\left(n=3\right.$ for each group, $\left.{ }^{\star} P<0.05\right)$. control. Splenic myeloid cells accumulated less radioactivity per cell during $\left[{ }^{18} \mathrm{~F}\right]$-FAC labeling than during $\left[{ }^{18} \mathrm{~F}\right]-$ FDG labeling (Figure 6). Myeloid cells and $\mathrm{CD}^{+}$and $\mathrm{CD}^{+} \mathrm{T}$ cells all accumulated $\left.{ }^{[18} \mathrm{F}\right]-\mathrm{FAC}$ at levels greater than the naive control. B cells retained levels of $\left[{ }^{18} \mathrm{~F}\right]-\mathrm{FAC}$ similar to those of the control population.

In the DLN, the most $\left[{ }^{18} \mathrm{~F}\right]-\mathrm{FDG}$ per cell was accumulated by CD11 $b^{\text {hi }}$ myeloid cells, approximately 100 -fold more than naive lymphocytes. $\mathrm{CD}^{+}$and $\mathrm{CD}^{+} \mathrm{T}$ cells also retained $\left[{ }^{18} \mathrm{~F}\right]$-FDG at levels greater than that of the naive control, but at magnitudes almost 10 -fold lower than the innate cell types. B cells did not retain significantly more probe per cell than the control population. In marked contrast to $\left[{ }^{18} \mathrm{~F}\right]-\mathrm{FDG},\left[{ }^{18} \mathrm{~F}\right]-\mathrm{FAC}$ accumulation in the DLN was greatest in CD8 ${ }^{+} \mathrm{T}$ cells. CD $11 \mathrm{~b}^{\text {hi }}$ cells, $\mathrm{CD} 4^{+} \mathrm{T}$ cells, and $B$ cells did not retain significant levels of probe per cell compared with naive lymphocytes.

In the sarcoma, myeloid cells accumulated the highest levels of $\left[{ }^{18} \mathrm{~F}\right]-\mathrm{FDG}$. CD4 ${ }^{+}$and $\mathrm{CD}^{+} \mathrm{T}$ cells also accumulated $\left[{ }^{18} \mathrm{~F}\right]-\mathrm{FDG}$ at levels substantially greater than naive lymphocytes. There were too few B cells at this site to routinely analyze for accumulation of either probe. Of the cell types analyzed with $\left[{ }^{18} \mathrm{~F}\right]-\mathrm{FAC}$, only $\mathrm{CD}^{+} \mathrm{T}$ cells retained probe at levels substantially greater than naive lymphocytes.

These results further demonstrate that $\left[{ }^{18} \mathrm{~F}\right]$-FDG and $\left[{ }^{18} \mathrm{~F}\right]-\mathrm{FAC}$ have different patterns of accumulation in innate and adaptive immune cells in vivo. We found that both probes accumulated in isolated $\mathrm{T}$ cell populations. Based on our findings in the ex vivo probe accumulation assay with $\left[{ }^{3} \mathrm{H}\right]-\mathrm{FAC}$ and previous studies of glucose utilization in T cells, retention of these probes is related in large part to activation-induced cell proliferation. In contrast, the myeloid cells accumulated large amounts of $\left[{ }^{18} \mathrm{~F}\right]-\mathrm{FDG}$ compared with $\left[{ }^{18} \mathrm{~F}\right]-\mathrm{FAC}$, suggesting that these cells are highly active for glycolysis in a manner that is independent of deoxycytidine salvage activity.
$A$ defective adaptive immune response leads to reduced $\left[{ }^{18} F\right]-F D G$ and $\left[{ }^{18} \mathrm{~F}\right]-\mathrm{FAC}$ signal in lymphoid organs but not the tumor. The MSV/MuLV model is an example of a cell-mediated antitumor response where $\mathrm{T}$ cells are stimulated by viral antigens to proliferate and traffic to the rhabdomyosarcoma, where they function to kill virally infected cells. To determine whether imaging glycolysis or deoxycytidine salvage is sensitive to changes in the number of T cells, we inoculated CB17 SCID/SCID mice (deficient for T and B cells) with MSV/MuLV and performed $\left[{ }^{18} \mathrm{~F}\right]-\mathrm{FAC}$ and $\left[{ }^{18} \mathrm{~F}\right]-\mathrm{FDG}$ microPET/CT 13 and 14 days after inoculation, respectively. MSV/MuLV-infected immunecompetent C57BL/ 6 mice, similar to those in Figure 1, A and B, were scanned with $\left[{ }^{18} \mathrm{~F}\right]-\mathrm{FAC}$ and $\left[{ }^{18} \mathrm{~F}\right]-\mathrm{FDG}$ for comparison (Figure $7 \mathrm{~A}$ ). $\mathrm{MSV} / \mathrm{MuLV}$-infected CB17 ${ }^{\mathrm{SCID} / \mathrm{SCID}}$ mice showed a reduction in $\left[{ }^{18} \mathrm{~F}\right]-\mathrm{FDG}$ spleen signal compared with immune-competent mice, but the difference in intensity varied between mice and was not statistically significant. Although CB17 SCID/SCID mice lack adaptive immunity, they contain a large percentage of splenic CD $11 b^{\text {hi }}$ innate cells that are potentially activated with viral challenge and may account for the $\left.{ }^{18} \mathrm{~F}\right]-F D G$ signal in this tissue. A 5-fold reduction in $\left[{ }^{18} \mathrm{~F}\right]$-FAC spleen signal was observed in immune-deficient mice compared with tumor-bearing C57BL/6 animals (Figure 7B).

$\left[{ }^{18} \mathrm{~F}\right]$-FAC and $\left[{ }^{18} \mathrm{~F}\right]-\mathrm{FDG}$ both consistently show high levels of accumulation in the DLNs of C57BL/ 6 mice. CB17 SCID/SCID mice are defective for lymphocyte production and lack developed lymph node tissue. Compared with that in immune-competent mice, FDG PET signal was reduced 7-fold in this region, while FAC signal was reduced 3 -fold.

Tumors in CB17 SCID/SCID and C57BL/6 mice accumulated $\left[{ }^{18} \mathrm{~F}\right]-\mathrm{FDG}$ to similar levels (Figure $7 \mathrm{~B}$ ). High rates of glycolysis in tumor cells and infiltrating myeloid cells likely contribute to $\left[{ }^{18} \mathrm{~F}\right]-F D G$ signal in the tumor of both immune-competent and immune-deficient animals. This baseline signal made it difficult 
to assess the presence of adaptive immune cells at this site. In stark contrast, $\left[{ }^{18} \mathrm{~F}\right]-\mathrm{FAC}$ accumulation in the tumor was low in immune-competent mice, and this signal was not changed in the immune-deficient condition, even in the absence of functional adaptive immune cells at this site. From our results in Figure 2, A and B, and Figure 4, we suspect that lower $T$ cell density in the tumor coupled with lower deoxycytidine salvage activity in tumor-infiltrating effector-memory cells results in the low levels of $\left[{ }^{18} \mathrm{~F}\right]$-FAC signal observed in this tissue.

\section{Discussion}

We investigated the capacity of PET imaging probes for two distinct metabolic pathways to label different cell types during an immune response. In vivo imaging of glycolysis and deoxycytidine salvage with $\left[{ }^{18} \mathrm{~F}\right]-\mathrm{FDG}$ and $\left[{ }^{18} \mathrm{~F}\right]-\mathrm{FAC}$ in mice challenged with a retrovirus-induced sarcoma showed intense signal in the DLNs and spleen. $\left[{ }^{18} \mathrm{~F}\right]-\mathrm{FDG}$ also accumulated to high levels in the tumor region compared with $\left[{ }^{18} \mathrm{~F}\right]$-FAC. Immunohistochemical analysis showed that viral infection resulted in increased density of diverse innate and adaptive immune cell types in these tissues.

Isolation and analysis of the immune cells present in lymphoid tissues and tumors showed that different cell types had different glycolytic and deoxycytidine salvage activities. Ex vivo labeling showed that $\left[{ }^{3} \mathrm{H}\right]-2 \mathrm{DG}$ was retained only in $\mathrm{CD} 11 \mathrm{~b}^{\text {hi }}$ myeloid cells in the tumor and spleen during the anti-MSV/MuLV response. $\left[{ }^{18} \mathrm{~F}\right]-F D G$ accumulation in innate immune cells was predominant in the spleen, DLN, and tumor during in vivo labeling of infected mice. Conversely, in vivo labeling of innate immune cells with $\left[{ }^{18} \mathrm{~F}\right]-\mathrm{FAC}$ resulted in much less radioactivity accumulation per cell compared with $\left[{ }^{18} \mathrm{~F}\right]$-FDG. Glycolytic metabolism is critical to myeloid cell function in low-oxygen inflammatory environments (1), so elevated accumulation of probes for glycolysis in these cells was not surprising. Our findings support observations that probe accumulation in myeloid cells may constitute a significant portion of observed signal during [ $\left.{ }^{18} \mathrm{~F}\right]$-FDG PET scans (33-35).

Glycolysis is also critical to $T$ cells during activation-induced clonal expansion. Aerobic glycolysis resulting from mitogen stimulation in oxygen-rich conditions leads to high levels of intracellular glucose that drive membrane and protein biosynthesis and enable proliferation $(2,31)$. Ex vivo [ $\left.{ }^{3} \mathrm{H}\right]-2 \mathrm{DG}$ accumulation analysis did not show appreciable probe accumulation in highly proliferative immune cell types such as $\mathrm{CD}^{+} \mathrm{T}$ cells during the anti-MSV/MuLV response. We found that these cells expressed much lower levels of the glucose transporter Glut1 compared with T cells stimulated in vitro with anti-CD3 and IL-2. In vivo labeling of MSV/MuLV-infected mice with $\left[{ }^{18} \mathrm{~F}\right]$-FDG detected accumulation of this probe in $\mathrm{T}$ cell populations in the spleen, DLN, and tumor, but generally these signals were not as high as those observed in innate immune cells.

Under hypoxic conditions, glucose is shunted away from biosynthetic pathways toward energy production, lowering proliferative capacity (36). Thus, $\left[{ }^{18} \mathrm{~F}\right]-\mathrm{FDG}$ PET may have a dual specificity during in vivo imaging: $\left[{ }^{18} \mathrm{~F}\right]-\mathrm{FDG}$ accumulates in cells both during mitogen-stimulated aerobic glycolysis and during hypoxiainduced anaerobic glycolysis.

FAC accumulated in both innate and adaptive cells in vitro and in vivo. Probe accumulation correlated with measurements of immune cell proliferation, leading us to conclude that $\left[{ }^{18} \mathrm{~F}\right]$-FAC signal in vivo is a site-specific measurement of immune cell proliferation. $\left[{ }^{18} \mathrm{~F}\right]$-FLT is a nucleoside-based PET probe that measures thymidine salvage. FLT is taken into cells by membrane-bound transporters and phosphorylated and trapped by the S-phase-specific kinase thymidine kinase 1 (TK1) $(37,38)$. TK1 is expressed in rapidly proliferating tissues in humans such as bone marrow and in a variety of tumor types. $\left[{ }^{18} \mathrm{~F}\right]$-FLT PET signal correlates with the proliferative index of human tumors both clinically and in xenograft models (39). The utility of $\left[{ }^{18} \mathrm{~F}\right]$-FLT in measuring cell proliferation suggests that this probe may be useful in measuring the expansion of immune cell populations during a response.

The differences between $\left[{ }^{18} \mathrm{~F}\right]-\mathrm{FAC}$ and $\left[{ }^{18} \mathrm{~F}\right]$-FLT PET and their potential relative utilities have not yet been investigated. Mice and rats have high serum concentrations of thymidine that compete with $\left[{ }^{18} \mathrm{~F}\right]-\mathrm{FLT}$ and limit its accumulation in tissues $(40,41)$. This makes direct in vivo comparisons with $\left[{ }^{18} \mathrm{~F}\right]-\mathrm{FAC}$ difficult in rodent models. We measured the accumulation of $\left[{ }^{3} \mathrm{H}\right]$-FLT in immune cells isolated from the tissues of MSV/MuLV-infected mice ex vivo to circumvent this issue of endogenous thymidine. We did not observe significant signal in these cells compared with naive cells (Supplemental Figure 2). In contrast, pulse labeling with $\left[{ }^{3} \mathrm{H}\right]$-thymidine showed robust accumulation in a manner that mirrored $\left[{ }^{3} \mathrm{H}\right]$-FAC accumulation (Supplemental Figure 2). Thus, although murine immune cells are active for thymidine salvage, they appear unable to retain FLT. The specific membrane transporters that mediate uptake of FLT have yet to be defined. It is possible that there is a species difference in FLT transport between human and mouse cells that hinders probe accumulation in mouse tissues. Serum thymidine does not limit $\left[{ }^{18} \mathrm{~F}\right]$-FLT accumulation in humans, and human tissues apparently express FLT transporters, which perhaps will eventually allow clinical comparisons of these probes.

An important distinction in the utility of $\left[{ }^{18} \mathrm{~F}\right]$-FLT and $\left[{ }^{18} \mathrm{~F}\right]$-FAC in clinical imaging relates to the enzymes that mediate intracellular trapping of each probe. Intracellular FAC accumulation depends on DCK activity. Adaptive immune cells are particularly sensitive to loss of DCK; knocking out this gene in mice results in drastically reduced numbers of T and B cells (20). Tumors, however, can often overcome a lack of DCK and continue to proliferate. Tumors treated with nucleoside analog prodrugs that are activated by DCK (for example, gemcitabine and cytarabine) may eventually lose tumor DCK expression, resulting in resistance to this class of drugs and disease progression $(42,43)$. Thus, accumulation of FAC, unlike FLT, in tumors does not depend as much on proliferative index as it does on the level of DCK expression. Visualizing changes in immune cell proliferative activity in tumors with $\left[{ }^{18} \mathrm{~F}\right]$-FAC PET may be useful in instances where there is low DCK expression in tumor cells due to tissue-specific expression patterns or as a result of prolonged nucleoside analog chemotherapy.

The different specificities of $\left[{ }^{18} \mathrm{~F}\right]-\mathrm{FDG}$ and $\left[{ }^{18} \mathrm{~F}\right]$-FAC suggest that these probes may be useful in evaluating therapies that target different cellular components of the immune system. [18 F]-FAC, for example, may detect cell populations responsive to antiproliferative immune suppressants or nucleoside analog prodrugs and may be more sensitive than $\left[{ }^{18} \mathrm{~F}\right]-\mathrm{FDG}$ in measuring the effects of such drugs. Imaging immune cell proliferation with probes such as $\left[{ }^{18} \mathrm{~F}\right]$-FAC may also be useful in monitoring cell expansion and engraftment after bone marrow transplantation or adoptive cell transfer. Owing to its robust accumulation in innate immune cells, $\left[{ }^{18} \mathrm{~F}\right]-F D G$ PET may be more useful in evaluating the effects of therapies that target inflammatory mediators. The most notable of these are the anti-TNF- $\alpha$ agents used for inflammatory bowel disease, rheumatoid arthritis, and psoriasis (reviewed in ref. 44). 
Measuring the activity of anti-TNF- $\alpha$ therapy with $\left[{ }^{18} \mathrm{~F}\right]-\mathrm{FDG}$ PET could guide dosing regimens and predict resistance.

\section{Methods}

Animals and MSV/MuLV inoculation. C57BL/6 and CB $17^{\text {SCID/SCID animals }}$ were bred and maintained according to the guidelines of the UCLA Department of Laboratory Animal Medicine (DLAM). All animal studies were carried out using protocols approved by DLAM. MSV/MuLV stocks were produced as reported previously (45). Six- to 14 -week-old C57BL/ 6 animals were inoculated in the shoulder muscle with $100 \mu \mathrm{l}$ of a 1:800 dilution of the viral stock solution in PBS. Six- to 12-week-old CB17 SCID/SCID animals were given intramuscular inoculations of $100 \mu \mathrm{l}$ of the MSV-MuLV stock solution diluted 1:1,000 in PBS.

MicroPET/CT imaging. Mice were warmed under gas anesthesia ( $2 \%$ isoflurane) and injected intravenously with $200 \mu \mathrm{Ci}$ of either $\left[{ }^{18} \mathrm{~F}\right]$-FDG or $\left[{ }^{18} \mathrm{~F}\right]$ FAC, followed by 1 hour uptake. Following uptake, mice were positioned in an imaging chamber for sequential imaging with the Siemens Preclinical Solutions microPET Focus 220 and MicroCAT II CT systems (Siemens). MicroPET data were acquired for 10 minutes and reconstructed with a statistical maximum a posteriori (MAP) probability algorithm into multiple frames (46). MicroPET and CT images were coregistered as previously described (47). Quantification of PET signal in specific anatomical regions was performed by drawing 3D ROIs using AMIDE software (http://amide. sourceforge.net/) (48). The mean intensity of the ROI, based on the percent injected dose per gram, was normalized to a background ROI drawn around uninfected muscle in the same animal (21). Data are presented as fold change over background. Images are presented here using a falsecolor scale that is proportional to tissue concentration of positron-labeled probe: red represents the highest concentrations, with yellow, green, and blue corresponding to sequentially lower values.

Whole-body autoradiography. Tumor-bearing mice were injected intravenously with $1 \mathrm{mCi}$ of either $\left[{ }^{18} \mathrm{~F}\right]-\mathrm{FDG}$ or $\left[{ }^{18} \mathrm{~F}\right]$-FAC and killed 1 hour later. Mice were embedded in 3\% carboxymethylcellulose and frozen in liquid nitrogen. Sections $(100 \mu \mathrm{m})$ were cut using a Leica CM3600 XP cryomacrotome, exposed overnight on BAS-TR2025 imaging screens (FujiFilm Life Science) at $-20^{\circ} \mathrm{C}$, and visualized using a BAS-5000 phosphor imager (FujiFilm Life Science).

Cryosectioning and immunohistochemistry. Tumors, spleens, and DLNs were harvested, embedded, and stained as described previously (45). Frozen sections were stained with the following biotinylated antibodies: rat anti-CD11b (clone: M1/70), rat anti-B220 (clone: RA3-6B2), rat anti-CD4 (clone: GK 1.5), and rat anti-CD8 (clone: 53.6.7). Peroxidase-conjugated Streptavidin-HRP (Dako) was used as a secondary reagent for the biotinylated antibodies. To assess the distribution of each immune cell type in the different tissues, positively stained cells from 10 random $\times 40$ fields of view on at least 3 different sections were counted. The average number of positive cells from these counts was divided by the area of the field of view $\left(0.047 \mathrm{~mm}^{2}\right)$ to give an approximate measurement of cells $/ \mathrm{mm}^{2}$.

Dissociation of tissues from MSV/MuLV-infected mice. Tumors, DLNs, and spleens from MSV/MuLV-infected C57BL/6 animals were removed 14 days after inoculation. The tissues from 3 animals were pooled for each experiment. Tumors were minced and incubated for 40 minutes at $37^{\circ} \mathrm{C}$ in HEPES buffer containing DNAse, $1 \mathrm{mg} / \mathrm{ml}$ collagenase and hyaluronidase. Tumor pieces were then pressed through a $70-\mu \mathrm{m}$ cell strainer and centrifuged through a Nycodenz gradient (Accurate Chemical and Scientific Corp.) for 20 minutes at $754 \mathrm{~g}$. Cells were collected from the interface for antibody staining and cell sorting. Spleens were cut in small pieces and incubated for 40 minutes at $37^{\circ} \mathrm{C}$ in HEPES buffer containing DNAse and $1 \mathrm{mg} / \mathrm{ml}$ collagenase. Spleen pieces were pressed through a $70-\mu \mathrm{m}$ cell strainer and washed, and red blood cells were lysed in $0.8 \%$ ammonium chloride. Single cells were then stained for cell sorting. The capsules of DLNs and naive lymph nodes were disrupted with needles, and the tissue was pressed through a 70- $\mu \mathrm{m}$ cell strainer and stained for cell sorting.

Cell sorting and flow cytometry. Single-cell suspensions from the tumor, DLNs, and spleen were stained with the following fluorochrome-conjugated antibodies from BD Biosciences - Pharmingen: anti-CD4-PE, antiCD8-PE-Cy7, anti-B220- or anti-CD19-APC-Cy7, and anti-CD11b-FITC. Four-color cell sorting was performed on the FACSAria automated cell sorter (BD Biosciences). To assess activation status, $\mathrm{CD}^{+} \mathrm{T}$ cell populations were stained with anti-CD62L-APC, anti-CD44-APC-Cy7, and anti-CD25$\mathrm{APC}$ from BD Biosciences - Pharmingen for flow cytometric analysis.

Ex vivo probe accumulation assay and propidium iodide analysis. Sorted cell populations were split into 3 aliquots. Two aliquots were resuspended in X-Vivo-15 media (Lonza) or glucose-free DMEM (MediaTech) supplemented with glutamine, penicillin/streptomycin, and 2-ME. Cells from these aliquots $\left(10^{5}\right)$ were placed in wells of a 96-well $0.22-\mu \mathrm{m}$ Multiscreen filter bottom plate (Millipore) in triplicate and preincubated for 20 minutes at $37^{\circ} \mathrm{C}$ and $5 \% \mathrm{CO}_{2} \cdot\left[{ }^{3} \mathrm{H}\right]$-FAC, $\left[{ }^{3} \mathrm{H}\right]$-FLT, or $\left[{ }^{3} \mathrm{H}\right]$-thymidine $(1 \mu \mathrm{Ci})$ was diluted in $\mathrm{X}$-Vivo media and added to cells preincubated in X-Vivo. $\left[{ }^{3} \mathrm{H}\right]-2 \mathrm{DG}$ $(1 \mu \mathrm{Ci})$ diluted in glucose-free DMEM was added to cells preincubated in glucose-free conditions. All tritium-labeled compounds were purchased from Moravek Biochemicals. Cells were pulse labeled with probe for 1 hour at $37^{\circ} \mathrm{C}$ and $5 \% \mathrm{CO}_{2}$. After labeling, the plate was washed 5 times with cold $5 \%$ RPMI using the Multiscreen vacuum manifold (Millipore). Washed plates were dried, and $100 \mu \mathrm{l}$ of scintillation fluid was added to each well. Accumulated radioactivity was counted using a BetaMax plate reader (PerkinElmer). Radiation counts were normalized to the specific activity of each probe and presented as femtomoles per $10^{5}$ cells. The remaining aliquot containing $10^{5}$ cells was fixed in $70 \%$ ethanol for at least 12 hours at $-20^{\circ} \mathrm{C}$ and stained with propidium iodide according to standard protocols. The fraction of cells in $\mathrm{S}_{-} \mathrm{G}_{2}-\mathrm{M}$ was assessed on a FACSCanto (BD).

In vitro $T$ cell stimulation and Glut1 immunostaining. Whole mouse splenocytes were isolated as described above, and $\mathrm{T}$ cells were stimulated for 48 hours with hamster anti-mouse anti-CD3 $(0.3 \mu \mathrm{g} / \mathrm{ml})$ and rhIL-2 (400 IU/ml). For analysis of Glut1 expression, primary cells were lysed in $50 \mu \mathrm{l}$ modified RIPA buffer: $50 \mathrm{mM}$ Tris- $\mathrm{HCl}$ ( $\mathrm{pH} 6.8$ ), $150 \mathrm{mM} \mathrm{NaCl}$, $1 \mathrm{mM}$ EDTA, $0.3 \%$ SDS, $1 \%$ sodium deoxycholate, $1 \% \mathrm{NP}-40$, and complete protease inhibitor cocktail (Roche). Five micrograms total lysate/lane was loaded in $5 \times$ SDS loading dye without boiling onto a $4 \%-20 \%$ precast gel (Pierce) and subjected to gel electrophoresis. Proteins were subsequently transferred to nitrocellulose membranes. Post-transfer membranes were blocked for 1 hour in PBS-0.05\% Tween (PBST) containing 5\% nonfat milk at room temperature (RT). Anti-Glut1 (polyclonal rabbit antibody, Abcam) was diluted in PBST-5\% milk at $550 \mathrm{ng} / \mathrm{ml}$ and incubated for 2 hours at RT. Equal loading was determined by reprobing the membrane with rabbit anti-ERK2 (Santa Cruz Biotechnology Inc.) at $50 \mathrm{ng} / \mathrm{ml}$ in PBST-5\% milk. Membranes were washed in PBST, incubated 1 hour at RT in secondary goat anti-rabbit HRP (Bio-Rad) diluted 1:15,000 in PBST-5\% milk, and washed again in PBST. Antibody binding was detected using Chemiluminescent HRP substrate (Millipore).

In vivo probe accumulation analysis. C57BL/6 mice inoculated with MSV/ MuLV 12-15 days previously were injected with $1 \mathrm{mCi}$ of $\left[{ }^{18} \mathrm{~F}\right]-\mathrm{FDG}$ or $\left[{ }^{18} \mathrm{~F}\right]-\mathrm{FAC}$. Spleens, DLNs, and tumors were removed and dissociated, and the different innate and adaptive immune cell types were isolated from each tissue as described above. Similar numbers of cells labeled with $\left[{ }^{18} \mathrm{~F}\right]-$ FDG and $\left[{ }^{18} \mathrm{~F}\right]-F A C$ were collected for each cell type. Mice that were not infected with MSV/MuLV were similarly injected with either probe, and whole lymphocyte populations were collected. The amount of radioactivity in each cell type was measured using a Wallac Wizard 3" 1480 Automatic Gamma Counter (PerkinElmer). 
Statistics. Data in bar graphs are presented as mean \pm SEM. Graph production and analysis were performed with GraphPad Prism software, version 5. Multiple group comparisons were done using the Student's $t$ test. Correlations were measured by linear regression analysis. $P$ values less than 0.05 were considered significant.

\section{Acknowledgments}

We thank Waldemar Ladno and Judy Edwards for assistance with microPET/CT imaging, Nagichettiar Satyamurthy and the cyclotron staff for the production of $\left[{ }^{18} \mathrm{~F}\right]-\mathrm{FDG}$ and $\left[{ }^{18} \mathrm{~F}\right]-\mathrm{FAC}$, Eric Gschweng for assistance with in situ staining, Howard Mak for expert animal care, and Barbara Anderson for help with preparation of the manuscript. O.N. Witte is an Investigator of the Howard Hughes Medical Institute. C.G. Radu was supported by In Vivo Cellular and Molecular
Imaging Centers Developmental Project Award NIH P50 CA86306, National Cancer Institute/NIH grant 5U54 CA119347, and the Dana Foundation. C.G. Radu received unrestricted support from Merck Research Laboratories. E. Nair-Gill was supported by NIH T32 GM08042 UCLA Medical Scientist Training Program and Interdisciplinary Training in Virology and Gene Therapy T32 A1065067.

Received for publication September 24, 2009, and accepted in revised form March 31, 2010.

Address correspondence to: Owen N. Witte, The Howard Hughes Medical Institute, 675 Charles E. Young Drive South, Los Angeles, California 90095, USA. Phone: 310.206.0386; Fax: 310.206.8822; E-mail: owenwitte@mednet.ucla.edu.
1. Cramer T, et al. HIF-1alpha is essential for myeloid cell-mediated inflammation. Cell. 2003; 112(5):645-657.

2. Fox CJ, Hammerman PS, Thompson CB. Fuel feeds function: energy metabolism and the T-cell response. Nat Rev Immunol. 2005;5(11):844-852.

3. Frauwirth KA, et al. The CD28 signaling pathway regulates glucose metabolism. Immunity. 2002;16(6):769-777.

4. Woodland RT, et al. Multiple signaling pathways promote B lymphocyte stimulator dependent B-cell growth and survival. Blood. 2008;111(2):750-760.

5. Pearce EL, et al. Enhancing CD8 T-cell memory by modulating fatty acid metabolism. Nature. 2009; 460(7251):103-107.

6. Phelps ME. PET Molecular Imaging and Its Biological Applications. New York, New York, USA: Springer; 2004.

7. Czernin J, Phelps ME. Positron emission tomography scanning: current and future applications. Annu Rev Med. 2002;53:89-112.

8. Radu CG, Shu CJ, Shelly SM, Phelps ME, Witte ON. Positron emission tomography with computed tomography imaging of neuroinflammation in experimental autoimmune encephalomyelitis. Proc Natl Acad Sci U S A. 2007;104(6):1937-1942.

9. Brewer $S$, et al. Molecular imaging of murine intestinal inflammation with 2-deoxy-2-[18F]fluoro-Dglucose and positron emission tomography. Gastroenterology. 2008;135(3):744-755.

10. Matsui T, et al. Inflammatory cytokines and hypoxia contribute to $18 \mathrm{~F}-\mathrm{FDG}$ uptake by cells involved in pannus formation in rheumatoid arthritis. J Nucl Med. 2009;50(6):920-926.

11. Stelljes M, et al. Clinical molecular imaging in intestinal graft-versus-host disease: mapping of disease activity, prediction, and monitoring of treatment efficiency by positron emission tomography. Blood. 2008;111(5):2909-2918.

12. Rudd JH, et al. Atherosclerosis inflammation imaging with 18F-FDG PET: carotid, iliac, and femoral uptake reproducibility, quantification methods, and recommendations. J Nucl Med. 2008;49(6):871-878.

13. Beckers C, et al. Assessment of disease activity in rheumatoid arthritis with (18)F-FDG PET. J Nucl Med. 2004;45(6):956-964.

14. Basu S, Chryssikos T, Moghadam-Kia S, Zhuang H, Torigian DA, Alavi A. Positron emission tomography as a diagnostic tool in infection: present role and future possibilities. Semin Nucl Med. 2009;39(1):36-51.

15. Munn DH, et al. Prevention of allogeneic fetal rejection by tryptophan catabolism. Science. 1998; 281(5380):1191-1193.

16. Bensinger SJ, et al. LXR signaling couples sterol metabolism to proliferation in the acquired immune response. Cell. 2008;134(1):97-111.

17. Yuk JM, et al. Vitamin D3 induces autophagy in human monocytes/macrophages via cathelicidin. Cell Host Microbe. 2009;6(3):231-243.

18. Laing RE, et al. Noninvasive prediction of tumor responses to gemcitabine using positron emission tomography. Proc Natl Acad Sci U S A. 2009; 106(8):2847-2852.

19. Arner ES, Eriksson S. Mammalian deoxyribonucleoside kinases. Pharmacol Ther. 1995;67(2):155-186.

20. Toy G, et al. Requirement for deoxycytidine kinase in T and B lymphocyte development. Proc Natl Acad Sci US A. 2010;107(12):5551-5556.

21 . Brewer S, et al. Epithelial uptake of [18F]1-(2'-Deoxy2 -Arabinofuranosyl) cytosine indicates intestinal inflammation in mice. Gastroenterology. 2010; 138(4):1266-1275.

22. Fefer A, McCoy JL, Glynn JP. Induction and regression of primary moloney sarcoma virus-induced tumors in mice. Cancer Res. 1967;27(9):1626-1631.

23. Milan G, Zambon A, Cavinato M, Zanovello P, Rosato A, Collavo D. Dissecting the immune response to moloney murine sarcoma/leukemia virus-induced tumors by means of a DNA vaccination approach. J Virol. 1999;73(3):2280-2287.

24. Schepers K, et al. Differential kinetics of antigenspecific CD4+ and CD8+ $\mathrm{T}$ cell responses in the regression of retrovirus-induced sarcomas. J Immunol. 2002;169(6):3191-3199.

25. Lamon EW, Klein E, Andersson B, Fenyo EM, Skurzak $\mathrm{HM}$. The humoral antibody response to a primary viral neoplasm (MSV) through its entire course in BALB-c mice. Int J Cancer. 1973;12(3):637-645.

26. Fueger BJ, et al. Impact of animal handling on the results of $18 \mathrm{~F}-\mathrm{FDG}$ PET studies in mice. J Nucl Med. 2006;47(6):999-1006.

27. Radu CG, et al. Molecular imaging of lymphoid organs and immune activation by positron emission tomography with a new [18F]-labeled 2 '-deoxycytidine analog. Nat Med. 2008;14(7):783-788.

28. Soler C, et al. Macrophages require different nucleoside transport systems for proliferation and activation. FASEB J. 2001;15(11):1979-1988.

29. Nelson BH, Willerford DM. Biology of the interleukin-2 receptor. Adv Immunol. 1998;70:1-81.

30. D'Cruz LM, Rubinstein MP, Goldrath AW. Surviving the crash: transitioning from effector to memory CD8+ T cell. Semin Immunol. 2009;21(2):92-98.

31. Jones RG, Thompson CB. Revving the engine: signal transduction fuels T cell activation. Immunity. 2007; 27(2):173-178.

32. Maciver NJ, Jacobs SR, Wieman HL, Wofford JA, Coloff JL, Rathmell JC. Glucose metabolism in lymphocytes is a regulated process with significant effects on immune cell function and survival. J Leukoc Biol. 2008;84(4):949-957.

33. Rosenbaum SJ, Lind T, Antoch G, Bockisch A. False-positive FDG PET uptake - the role of PET/
CT. Eur Radiol. 2006;16(5):1054-1065.

34. Shiraki N, et al. False-positive and true-negative hilar and mediastinal lymph nodes on FDG-PET - radiological-pathological correlation. Ann Nucl Med. 2004;18(1):23-28.

35. Kubota R, Yamada S, Kubota K, Ishiwata K, Tamahashi N, Ido T. Intratumoral distribution of fluorine-18-fluorodeoxyglucose in vivo: high accumulation in macrophages and granulation tissues studied by microautoradiography. J Nucl Med. 1992; 33(11):1972-1980.

36. Lum JJ, et al. The transcription factor HIF-1alpha plays a critical role in the growth factor-dependent regulation of both aerobic and anaerobic glycolysis. Genes Dev. 2007;21(9):1037-1049.

37. Bading JR, Shields AF. Imaging of cell proliferation: status and prospects. J Nucl Med. 2008; 49(suppl 2):64S-80S.

38. Shields AF. PET imaging with 18 F-FLT and thymidine analogs: promise and pitfalls. J Nucl Med. 2003; 44(9):1432-1434.

39. Schwartz JL, Tamura Y, Jordan R, Grierson JR, Krohn KA. Monitoring tumor cell proliferation by targeting DNA synthetic processes with thymidine and thymidine analogs. J Nucl Med. 2003;44(12):2027-2032.

40. Nottebrock H, Then R. Thymidine concentrations in serum and urine of different animal species and man. Biochem Pharmacol. 1977;26(22):2175-2179.

41. van Waarde A, et al. Selectivity of 18F-FLT and 18FFDG for differentiating tumor from inflammation in a rodent model. J Nucl Med. 2004;45(4):695-700.

42. Jordheim LP, et al. Characterization of a gemcitabine-resistant murine leukemic cell line: reversion of in vitro resistance by a mononucleotide prodrug. Clin Cancer Res. 2004;10(16):5614-5621.

43. Jordheim LP, Dumontet C. Review of recent studies on resistance to cytotoxic deoxynucleoside analogues. Biochim Biophys Acta. 2007;1776(2):138-159.

44. Tracey D, Klareskog L, Sasso EH, Salfeld JG, Tak PP. Tumor necrosis factor antagonist mechanisms of action: a comprehensive review. Pharmacol Ther. 2008;117(2):244-279.

45. Shu CJ, et al. Visualization of a primary anti-tumor immune response by positron emission tomography. Proc Natl Acad Sci U S A. 2005;102(48):17412-17417.

46. Qi J, Leahy RM, Cherry SR, Chatziioannou A, Farquhar TH. High-resolution 3D Bayesian image reconstruction using the microPET small-animal scanner. Phys Med Biol. 1998;43(4):1001-1013.

47. Chow PL, Stout DB, Komisopoulou E, Chatziioannou AF. A method of image registration for small animal, multi-modality imaging. Phys Med Biol. 2006;51(2):379-390.

48. Loening AM, Gambhir SS. AMIDE: a free software tool for multimodality medical image analysis. $\mathrm{Mol}$ Imaging. 2003;2(3):131-137. 